\title{
A comprehensive model for analysis of real-time optical performance of a solar power tower with a multi-tube cavity receiver
}

\author{
Yu Qiu ${ }^{\mathrm{a}}$, Ya-Ling $\mathrm{He}^{\mathrm{a}, *}$, Peiwen $\mathrm{Li}^{\mathrm{b}}$, Bao-Cun $\mathrm{Du}^{\mathrm{a}}$ \\ $a$ Key Laboratory of Thermo-Fluid Science and Engineering of Ministry of Education, School of Energy and Power \\ Engineering, Xi' an Jiaotong University, Xi' an, Shaanxi 710049, China \\ $b$ Department of Aerospace and Mechanical Engineering, The University of Arizona, Tucson, AZ 85721, USA \\ Corresponding author: Tel: 029-82665930,E-mail: yalinghe@xjtu.edu.cn
}

Abstract: A comprehensive model for analysis of the real-time optical performance of a Solar Power Tower (SPT) with a Multi-Tube Cavity Receiver (MTCR) was developed using Monte Carlo Ray Tracing (MCRT) method. After validation, the model was used to study the optical performance of the DAHAN plant. The model-obtained results show that the solar flux in the MTCR exhibits a significant non-uniformity, showing a maximum flux of $5.141 \times 10^{5} \mathrm{~W} \cdot \mathrm{m}^{-2}$ on the tubes. A comparison of the tracking models indicates that it is a good practice to treat the tracking errors as the random errors of the tracking angles when considering the random effect on the solar flux distribution. Study also indicates that multi-point aiming strategy of tracking helps homogenizing the flux and reducing the energy maldistribution among the tubes. Additionally, time-dependent optical efficiencies were investigated, and the yearly efficiency for the energy absorbed by the tubes was found to be $65.9 \%$. At the end of the study, the cavity effect on the efficiency was revealed quantitatively, which indicates that the optical loss can be reduced significantly by the cavity effect, especially when the coating absorptivity is relatively low. It is concluded that the present model is reliable and suitable for predicting both the detailed solar flux and the real-time efficiency of SPT.

Keywords: Solar power tower; Multi-tube cavity receiver; Optical model; Multi-point aiming strategy; Real-time solar flux distribution; Real-time efficiency

\section{Introduction}

Global energy consumption has increased rapidly with the economic growth over the past half century, and it has resulted in not only the tight global supply but also serious global environment

\footnotetext{
* Corresponding author. Tel.: +86-29-8266-5930; fax: +86-29-8266-5445.
}

E-mail address: yalinghe@xitu.edu.cn. 
issues. For example, the global warming caused by carbon dioxide emitted through fossil fuel combustion has become a pressing issue for years [1-3]. For solving these problems, renewable energy sources, including solar energy, wind energy, bioenergy, hydropower, geothermal energy, ocean energy, etc., are considered to be highly competitive candidates. Among these candidates, solar energy is the most bountiful resource. Efficient utilization of solar energy is being considered as one of the promising solutions to the challenges [4-8]. The Concentrating Solar Power (CSP) technology, mainly including the Solar Power Tower (SPT)[9-11], Parabolic Dish Collector[12-15], Parabolic Trough Collector [16-19], and linear Fresnel reflector[20-22], has become a promising choice to utilize solar energy during the past few decades $[23,24]$. Relatively, the SPT is considered as an advanced and promising technology for large scale utilization of solar energy[25].

A typical SPT consists of a heliostat field, a receiver mounted on a tower, thermal energy storage and conversion modules. There are four typical configurations of receivers including Multi-Tube Cavity Receiver (MTCR), Multi-Tube External Receiver (MTER), volumetric receiver, and direct-absorption receiver for SPT [26-28]. Among these configurations, the MTCR has been widely applied for the high efficiency [29]. In the SPT using a MTCR, the heliostats will track the sun and concentrate the sun rays into the MTCR firstly. Then, the solar radiation will be absorbed by the absorber tubes and walls after multiple reflections. It is commonly known that the absorbed solar flux on the tubes is exceedingly uneven and varies greatly over time, which would result in extreme fluctuant non-uniform temperature and stress, and lead to negative effects on the performance and safety of the system [30-32]. Hence, the accurate simulation of the real-time solar flux in MTCR and real-time optical efficiency of the system is of great importance for the performance optimization, system design, and safe operation of the SPT [33, 34].

Many studies have focused on this topic, and computer codes have been developed, such as UHC, DELSOL and HFLCAL based on convolution methods, MIRVAL, HFLD and SOLTRACE based on Monte Carlo Ray Tracing (MCRT) [33, 35]. In convolution methods, the solar flux concentrated by an elementary mirror is considered with an equivalent error cone calculated by convolutions of Gaussian distributions of the sun shape, the slope and tracking errors of the mirror [35]. MCRT is a statistical method in which a number of random solar rays are generated and traced 
in the collector[36]. In MCRT, the sun shape and the slope and tracking errors of the surfaces are calculated by probability density functions. The interactions (absorption, reflection, refraction, etc.) with the surfaces for each ray are determined by Monte Carlo method. The flux in an elementary surface in the receiver is proportional to the number of rays absorbed in the element. These tools have also been applied in performance prediction and optimization of the SPT. Vant-Hull et al. [34] used UHC to design the aiming strategies and control the incident flux on the cylinder receiver of Solar Two plant. Salomé et al. [9] used HFLCAL to control the incident flux on the MTCR's aperture of THEMIS plant. Rinaldi et al. [37] computed the incident flux on the simplified tube panels of a MTCR in PS10 by DELSOL3. Mecit et al. [38] used MIRVAL to compute the incident flux on the aperture of a particle receiver in the heliostat field at the National Solar Thermal Test Facility of Sandia National Laboratories. Yao et al. [39] developed HFLD and used it to compute the incident flux on the MTCR's aperture in DAHAN plant and optimize the heliostat field. Similar work has been done for DAHAN by Yu et al. [40], and the time-dependent incident flux on the simplified tube panels was revealed. Yellowhair et al. [33] used SOLTRACE to evaluate some novel complex receivers with fins for the enhancement of the solar radiation absorption. Sanchez-Gonzalez and Santana [41] also used SOLTRACE to simulate the incident flux on a cylinder receiver, and the results are used to validate a projection method for flux prediction.

Garcia et al.[35] indicated that the convolution methods and most MCRT models are limited to standard receiver geometries such as flat plate, cylinder, and simplified cavity receiver without considering the tubes and cavity effect, although they can predict the real-time optical performance which includes the real-time flux and efficiency. It is also found that there is almost no limit on geometries in SOLTRACE. However, it has no function to predict the real-time performance, because the sun position and heliostat tracking angles cannot be updated automatically in the code. The current status is that no studies have developed a model to manage both the complex geometry with complex optical processes in the MTCR of a SPT and the prediction of real-time optical performance.

To provide better studies to the optical system of SPT, present work focuses on developing a comprehensive optical model using Monte Carlo Ray Tracing (MCRT) [36, 42]. The main 
contributions are summarized as:

(1) The originality of this work is that an optical model which can manage both the complex geometry with intricate optical processes in a Solar Power Tower (SPT) using a Multi-Tube Cavity Receiver (MTCR) and the prediction of the real-time optical performance which consists of the real-time flux and optical efficiency was developed. A realistic SPT was simulated to illustrate the application of the model.

(2) The typical real-time non-uniform solar fluxes in the MTCR and real-time optical efficiency of the SPT were numerically obtained and discussed. The effects of tracking models and aiming strategies were investigated, and corresponding useful recommendations were offered.

(3) The real-time, daily and yearly optical efficiencies throughout the whole year were evaluated. The impact of cavity effect on optical efficiencies and optical loss were quantificationally revealed and analyzed.

\section{Physical model}

The DAHAN plant located at $40.4^{\circ} \mathrm{N}, 115.9^{\circ} \mathrm{E}$ in Beijing is considered as the physical model $[10,43]$. The heliostat field with 100 heliostats and a new designed molten salt MTCR including 30 panels are shown in Fig. 1 and Fig. 2, respectively. Every heliostat is composed of 64 facets with the size of $1.25 \mathrm{~m} \times 1.25 \mathrm{~m}$ and mounted on a $6.6 \mathrm{~m}$ pillar. These facets are carefully aligned to form a spherical surface. The tube panels are divided into three regions which are the (1) west panels, (2) middle panels and (3) east panels as shown in Fig. 2. The detailed parameters of DAHAN are given in Table 1. Due to the lack of published data, the slope and tracking errors of the heliostat are assumed to be the same as those of PS10 plant[37,44], where the tracking errors of the two axes of a heliostat are assumed to be equal to each other.

In the model, two aiming strategies are provided for the heliostat field. One is the traditional one-point aiming strategy, where all heliostats aim at the center of the MTCR's aperture, i.e. $\boldsymbol{O}$ in Fig. 2. The other is called multi-point aiming strategy, where the heliostat field is divided into several regions, and a specific aiming point is provided for each region. For present plant, the field is divided into five regions which are represented by different shapes and marked with $\mathrm{B}, \mathrm{C}, \mathrm{D}, \mathrm{E}, \mathrm{O}$ as shown in Fig. 1(b). Corresponding aiming points on the aperture are given in Fig. 2 and marked 
111 in the same way as those of the regions.

112

113

114

115

116

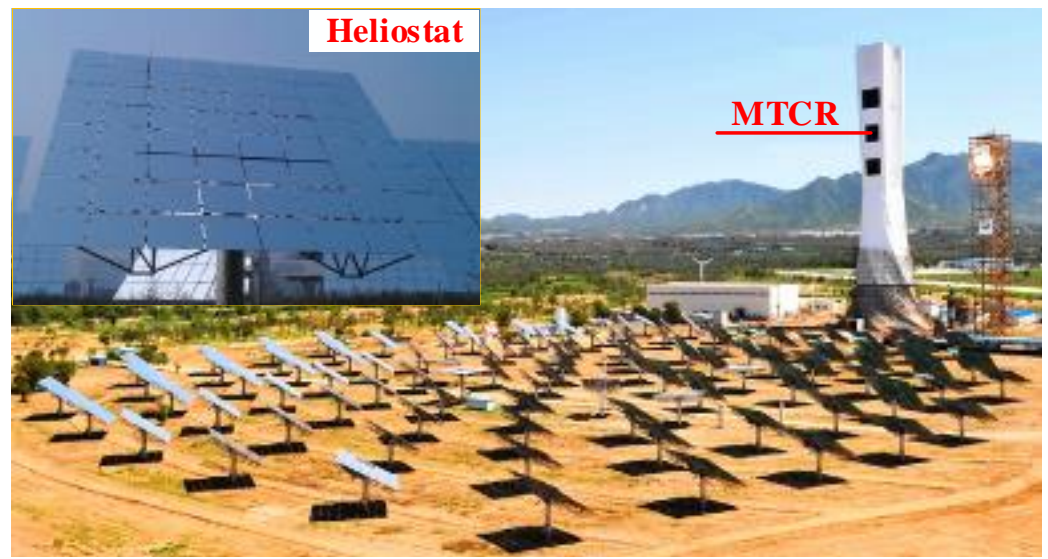

(a) Photo of the DAHAN heliostat field[40, 45]

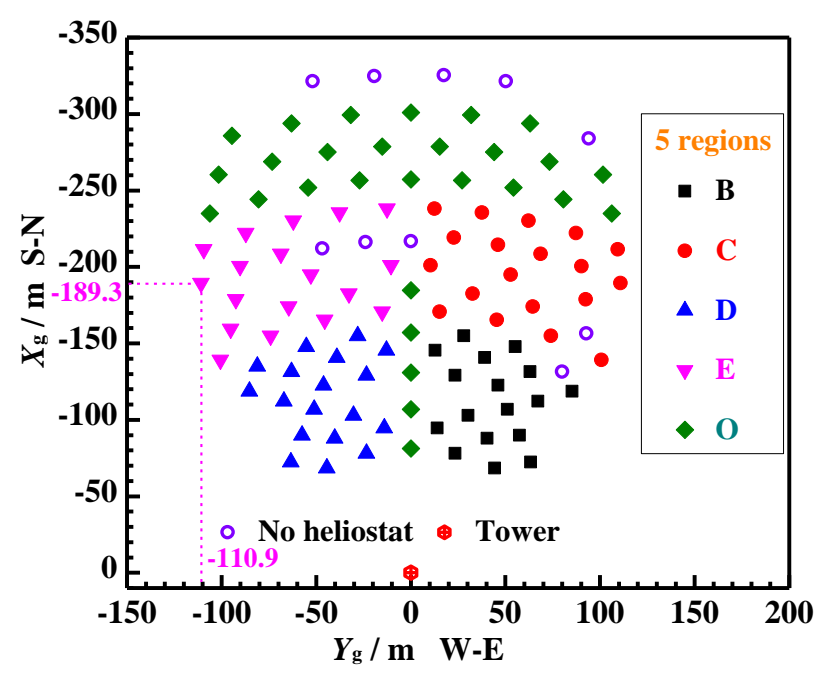

(b) Details of the field and 5 regions.

Fig. 1. Radial staggered heliostat field in DAHAN plant.

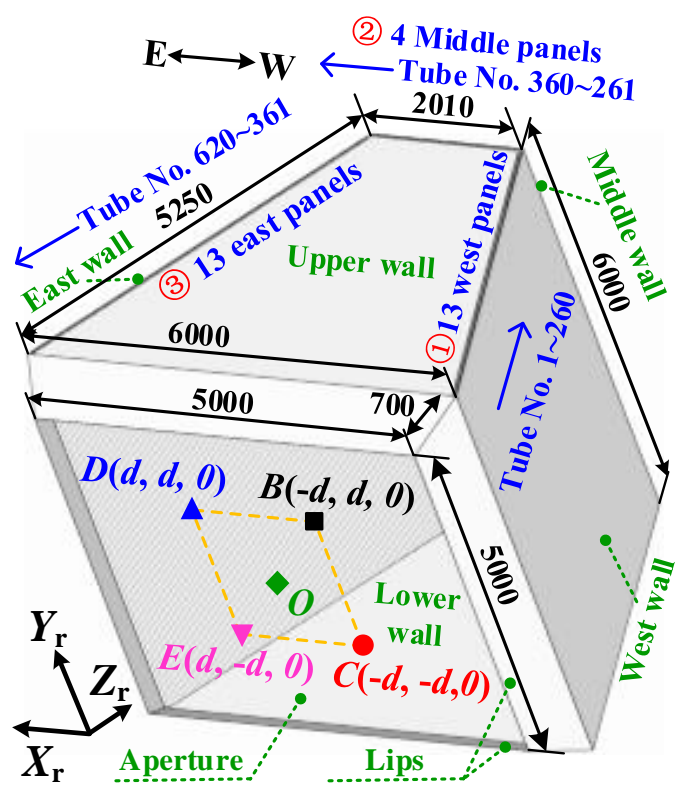

Fig. 2. Sketch of the MTCR in DAHAN plant. 
Table 1 Parameters and assumptions of DAHAN plant $[10,37,44,46]$.

\begin{tabular}{llll}
\hline Parameters & Dim. & Parameters & Dim. \\
\hline Heliostat number $n_{\mathrm{h}}$ & 100 & Tube distance in a panel & $1 \mathrm{~mm}$ \\
Heliostat shape & Spherical & Distance between panels & $1 \mathrm{~mm}$ \\
Heliostat width $W_{\mathrm{h}}$ & $10 \mathrm{~m}$ & Aperture height & $5 \mathrm{~m}$ \\
Heliostat height $L_{\mathrm{h}}$ & $10 \mathrm{~m}$ & Aperture width & $5 \mathrm{~m}$ \\
Heliostat center height & $6.6 \mathrm{~m}$ & Heliostat reflectivity $\rho_{\mathrm{h}, 1}$ & 0.9 \\
Tower height & $118 \mathrm{~m}$ & Heliostat cleanliness $\rho_{\mathrm{h}, 2}$ & 0.97 \\
Tower radius & $10 \mathrm{~m}$ & Altitude tracking error $\sigma_{\mathrm{te}, 1}=\sigma_{\mathrm{te}}$ & $0.46 \mathrm{mrad}$ \\
Receiver Height $H_{\boldsymbol{o}}$ & $78 \mathrm{~m}$ & Azimuth tracking error $\sigma_{\mathrm{te}, 2=\sigma_{\mathrm{te}}}$ & $0.46 \mathrm{mrad}$ \\
Receiver altitude $\alpha_{\mathrm{r}}$ & $25^{\circ}$ & Heliostat slope error $\sigma_{\mathrm{se}}$ & $1.3 \mathrm{mrad}$ \\
Panel number & 30 & Coating absorptivity $\alpha_{\mathrm{t}}$ & 0.9 \\
Tubes in a rear panel & 25 & Coating diffuse reflectance $\rho_{\mathrm{t}, \mathrm{d}}$ & 0.1 \\
Tubes in a side panel & 20 & Cavity wall absorptivity $\alpha_{\mathrm{w}}$ & 0.6 \\
Tube radius & $19 \mathrm{~mm}$ & Wall diffuse reflectance $\rho_{\mathrm{w}, \mathrm{d}}$ & 0.4 \\
\hline
\end{tabular}

\section{Mathematical model}

The transfer of a sunray in a SPT with a MTCR could be divided into two parts. One is the process in the heliostat field as shown in Fig. 3, and the other is the process within the MTCR as shown in Fig. 4. The first process mainly consists of four minor processes which are (1) photon initialization on the heliostat in the field, (2) shading of the tower or adjacent heliostats, (3) specular reflection on the heliostat, and (4) blocking of adjacent heliostats. The second part mainly includes two minor processes which are (1) diffuse and specular reflection on the tubes and cavity walls, and (2) absorption on the tubes and the walls. In the second part, the cavity effect which refers to the multiple reflections and absorptions on the tubes and walls should be considered carefully.

A real-time Monte Carol Ray Tracing (MCRT) model and corresponding code named after SPTOPTIC were developed to simulate these processes and calculate the real-time optical performance, with the flow chart shown in Fig. 5. In the model, several widely used assumptions are made as follows:

(1) The surface of each heliostat is assumed to be a continuous spherical surface by ignoring the narrow gaps among the facets [40]. The center of the spherical surface is assumed to coincide with the top of its pillar[40]. The tracking errors of two tracking axes for each heliostat and the slope error of the heliostat are assumed to approximately follow the Gaussian distribution[40, 47]. The 
aligned error of the facets can be ignored[41] or approximately considered as an equivalent part of the slope error[48].

(2) The rays which hit the same location on a heliostat are assumed to be within a cone with an apex angle of $9.3 \mathrm{mrad}$ for considering the shape effect of the sun [39, 49].

(3) The solar ray transfer in the MTCR can be simulated without considering the effect of the thermal radiation heat transfer in the receiver[14].

To describe the model, several Cartesian right-handed coordinate systems are established in Fig. 3. The ground system is defined as $X_{\mathrm{g}} Y_{\mathrm{g}} Z_{\mathrm{g}}$, where the tower base $\boldsymbol{G}$ is the origin, and $X_{\mathrm{g}}, Y_{\mathrm{g}}$, and $Z_{\mathrm{g}}$ points to the south, east, and zenith, respectively. The heliostat system is defined as $X_{\mathrm{h}} Y_{\mathrm{h}} Z_{\mathrm{h}}$, where the center of each heliostat $\boldsymbol{H}$ is the origin. $X_{\mathrm{h}}$ is horizontal, and $Y_{\mathrm{h}}$ is normal to the tangent plane at $\boldsymbol{H}$ and points upwards. $Z_{\mathrm{h}}$ is perpendicular to $X_{\mathrm{h}} Y_{\mathrm{h}}$ plane. The incident-normal system is defined as $X_{\mathrm{i}} Y_{\mathrm{i}} Z_{\mathrm{i}}$, where the point which is hit by the ray on the heliostat is the origin, and $Z_{\mathrm{i}}$ points towards the sun. $X_{\mathrm{i}}$ is horizontal and normal to $Z_{\mathrm{i}}$, and $Y_{\mathrm{i}}$ is perpendicular to $X_{\mathrm{i}} Z_{\mathrm{i}}$ plane and points upwards. The receiver system is defined as $X_{\mathrm{r}} Y_{\mathrm{r}} Z_{\mathrm{r}}$, where the aperture center is the origin. $X_{\mathrm{r}}$ points to the east, and $Y_{\mathrm{r}}$ points upwards. $Z_{\mathrm{r}}$ is perpendicular to $X_{\mathrm{r}} Y_{\mathrm{r}}$ plane. The tube system is defined as $X_{\mathrm{t}} Y_{\mathrm{t}} Z_{\mathrm{t}}$ and the tube center $\boldsymbol{T}$ is the origin. $X_{\mathrm{t}}$ is parallel to $X_{\mathrm{r}} Y_{\mathrm{r}}$, and $Y_{\mathrm{t}}$ is coincident with the tube centerline and points upwards. $Z_{\mathrm{t}}$ is normal to $X_{\mathrm{t}} Y_{\mathrm{t}}$ plane. The wall system is defined as $X_{\mathrm{w}} Y_{\mathrm{w}} Z_{\mathrm{w}}$ in the similar way as that of $X_{\mathrm{t}} Y_{\mathrm{t}} Z_{\mathrm{t}}\left(\right.$ Fig. 3). The local system on tube is defined as $X_{1} Y_{1} Z_{\mathrm{l}}$, and the relation between $X_{\mathrm{t}} Y_{\mathrm{t}} Z_{\mathrm{t}}$ and it is illustrated in Fig. 3. The transformation matrixes including $\boldsymbol{M}_{1} \sim \boldsymbol{M}_{14}$ among these systems are summarized in the Appendix.

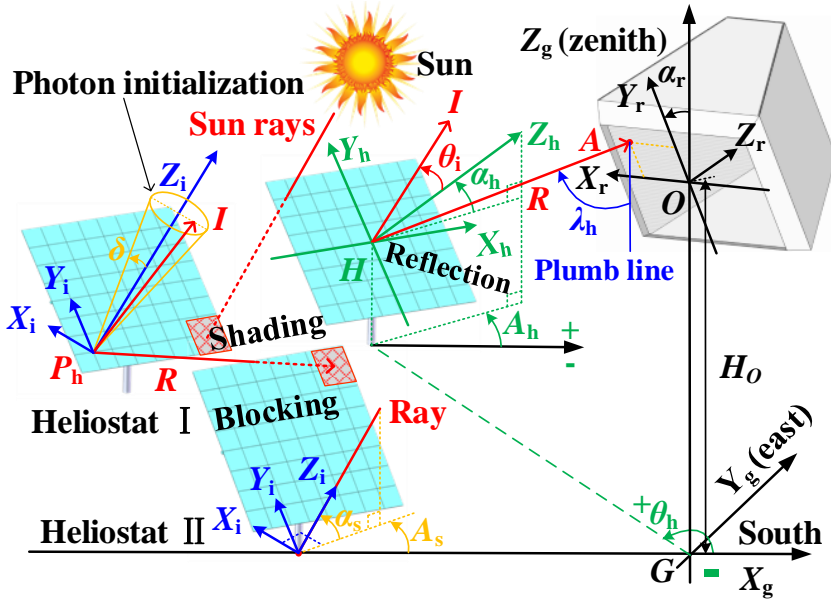

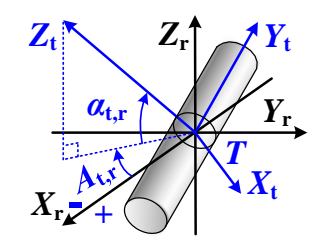

The tube, $X_{\mathrm{t}} Y_{\mathrm{t}} Z_{\mathrm{t}}$ and $X_{\mathrm{r}} Y_{\mathrm{r}} Z_{\mathrm{r}}$
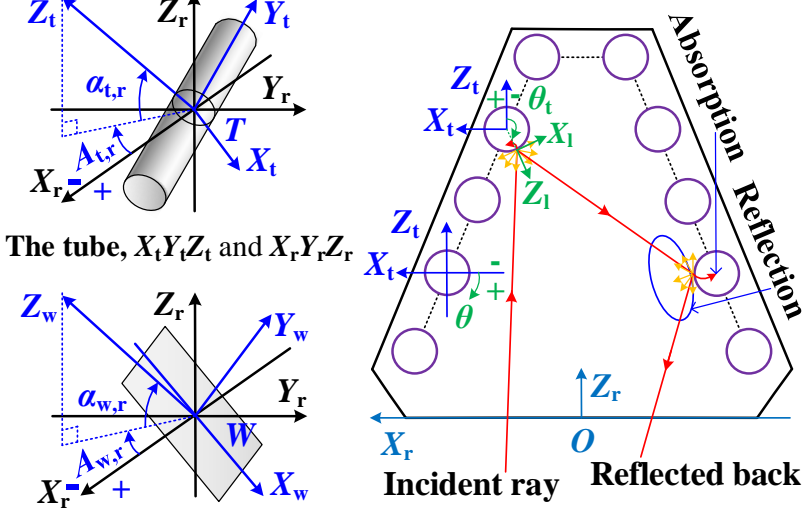

The wall, $X_{\mathrm{w}} Y_{\mathrm{w}} Z_{\mathrm{w}}$ and $X_{\mathrm{r}} Y_{\mathrm{r}} Z_{\mathrm{r}}$ Coordinate systems in MTCR

Fig. 3. Sketch of the SPT with a MTCR showing the solar ray transfer and coordinate systems. 


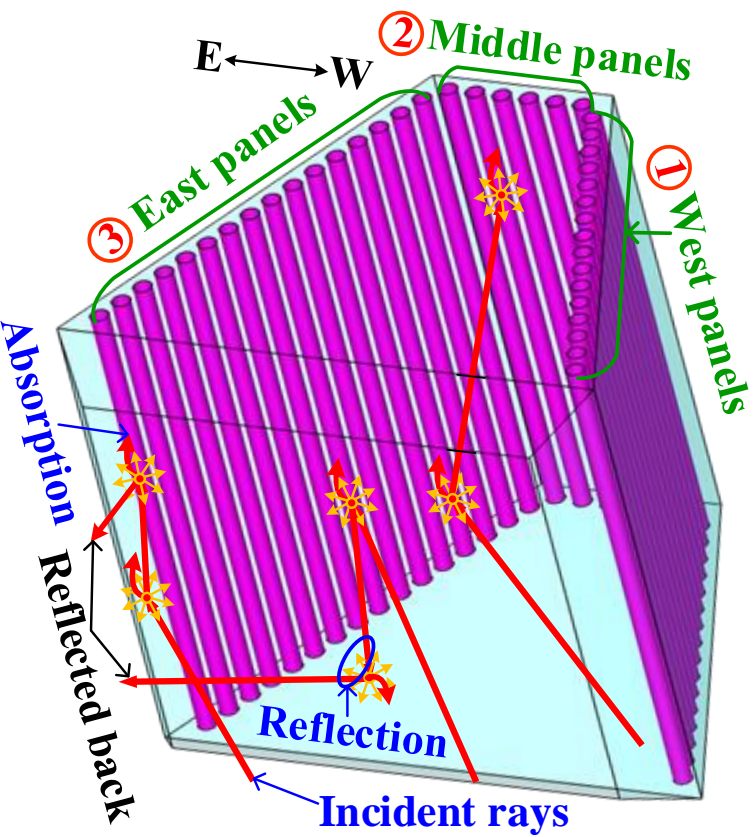

Fig. 4. Details of the optical processes in the MTCR.

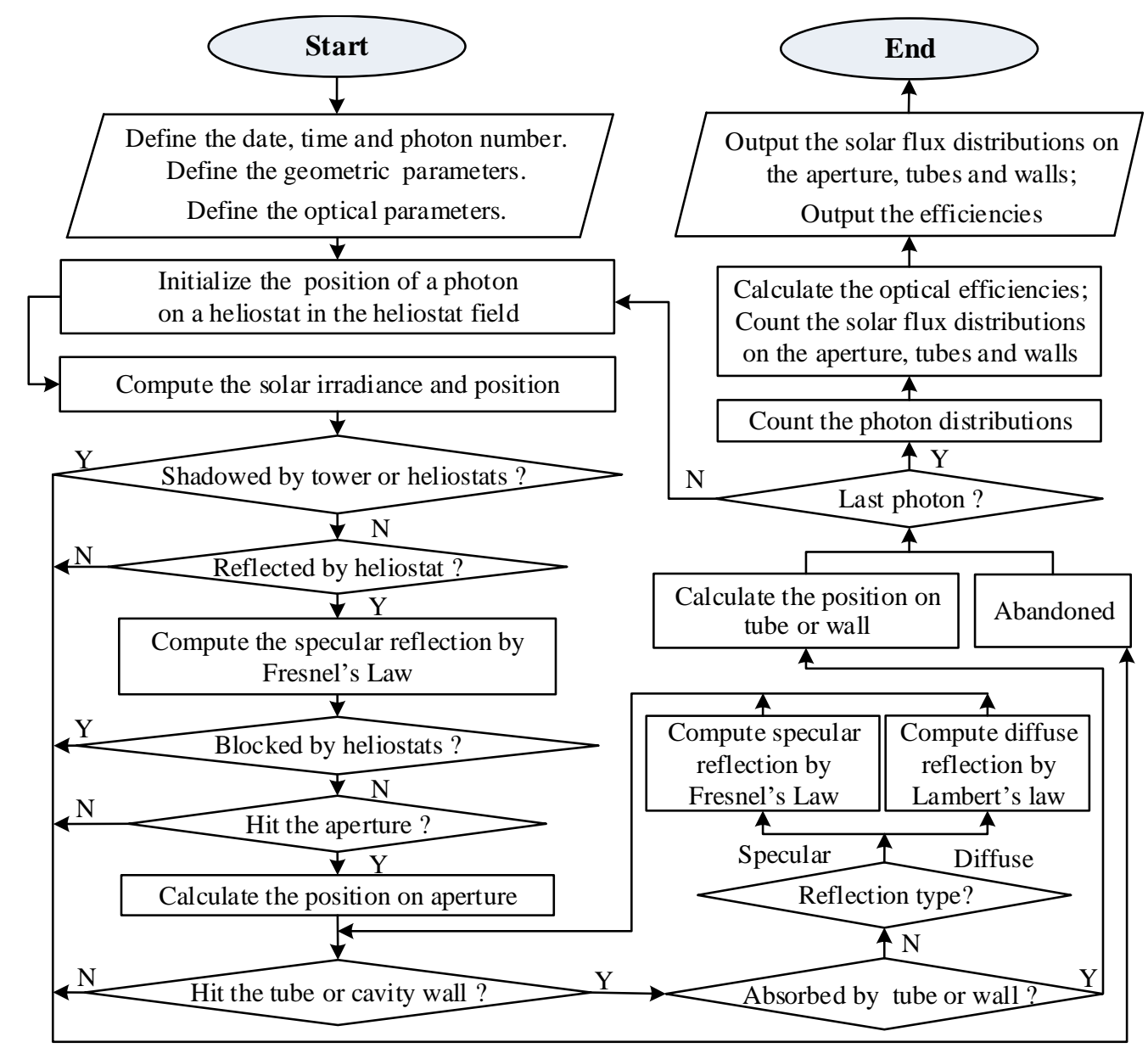

Fig. 5. The flow diagram of the SPTOPTIC code. 
170

The altitude $\left(\alpha_{\mathrm{h}}\right)$ and azimuth $\left(A_{\mathrm{h}}\right)$ of the heliostat's center normal are calculated by Eq.(1), where the quadrant ambiguity of $A_{\mathrm{h}}$ should be recognized when the sun rays come from the north [50]. The tracking errors are treated as the angles' errors (Model A) [51]. This treatment is different from another model (Model B) which treats the tracking errors as an equivalent slope error and calculates the total slope error by $\sqrt{\sigma_{\mathrm{se}}^{2}+\sigma_{\mathrm{te}, 1}^{2}+\sigma_{\mathrm{te}, 2}^{2}}[50]$.

$$
\alpha_{\mathrm{h}}=\sin ^{-1}\left(\frac{\sin \alpha_{\mathrm{s}}+\cos \lambda_{\mathrm{h}}}{2 \cos \theta_{\mathrm{i}}}\right)+R_{\mathrm{te}, 1}
$$

$$
A_{\mathrm{h}}=\tan ^{-1}\left(\frac{\sin \theta_{\mathrm{h}} \sin \lambda_{\mathrm{h}}-\sin A_{\mathrm{s}} \cos \alpha_{\mathrm{s}}}{\cos \theta_{\mathrm{h}} \sin \lambda_{\mathrm{h}}-\cos A_{\mathrm{s}} \cos \alpha_{\mathrm{s}}}\right)+R_{\mathrm{te}, 2}
$$

where $\theta_{\mathrm{h}}$ is the azimuth of the heliostat in the field, which is calculated using Eq.(2); $\lambda_{\mathrm{h}}$ which is the angle between the line $\boldsymbol{H} \boldsymbol{A}$ and local vertical is computed by Eq.(3); Given in Eq.(4) are $\boldsymbol{H}$ and $\boldsymbol{A}$ which are the heliostat's center and the aiming point in $X_{\mathrm{g}} Y_{\mathrm{g}} Z_{\mathrm{g}}$, respectively; $\theta_{\mathrm{i}}$ is the incident angle of the principle ray at the heliostat center; $\alpha_{\mathrm{s}}$ and $A_{\mathrm{s}}$ are the solar altitude and azimuth given in Eq.(6) and (7) [52], respectively; $R_{\mathrm{te}, 1} \sim N\left(0, \sigma_{\mathrm{te}, 1}^{2}\right)$ and $R_{\mathrm{te}, 2} \sim N\left(0, \sigma_{\mathrm{te}, 2}^{2}\right)$ are the tracking errors of $\alpha_{\mathrm{h}}$ and $A_{\mathrm{h}}$, respectively.

$$
\begin{aligned}
& \theta_{\mathrm{h}}=\cos ^{-1}\left(x_{\boldsymbol{H}, \mathrm{g}} / \sqrt{x_{\boldsymbol{H}, \mathrm{g}}^{2}+y_{\boldsymbol{H}, \mathrm{g}}^{2}}\right), y_{\boldsymbol{H}, \mathrm{g}} \geq 0 \\
& \lambda_{\mathrm{h}}=\cos ^{-1}\left[\left(z_{\boldsymbol{A}, \mathrm{g}}-z_{\mathrm{H}, \mathrm{g}}\right) / D_{H, A}\right] \\
& \boldsymbol{H}=\left[\begin{array}{lll}
x_{\boldsymbol{H}, \mathrm{g}} & y_{\boldsymbol{H}, \mathrm{g}} & z_{\boldsymbol{H}, \mathrm{g}}
\end{array}\right]^{\mathrm{T}}, \boldsymbol{A}=\left[\begin{array}{lll}
x_{\boldsymbol{A}, \mathrm{g}} & y_{\boldsymbol{A}, \mathrm{g}} & z_{\boldsymbol{A}, \mathrm{g}}
\end{array}\right]^{\mathrm{T}} \\
& \theta_{\mathrm{i}}=\cos ^{-1}\left[\frac{\sqrt{2}}{2} \sqrt{\sin \alpha_{\mathrm{s}} \cos \lambda_{\mathrm{h}}-\cos \alpha_{\mathrm{s}} \sin \lambda_{\mathrm{h}} \cos \left(\theta_{\mathrm{h}}-A_{\mathrm{s}}\right)+1}\right] \\
& \alpha_{\mathrm{s}}=\sin ^{-1}(\sin \varphi \sin \delta+\cos \varphi \cos \delta \cos \omega) \\
& A_{\mathrm{s}}=\cos ^{-1}\left(\frac{\sin \alpha_{\mathrm{s}} \sin \varphi-\sin \delta}{\cos \alpha_{\mathrm{s}} \cos \varphi}\right), \omega \leq 0 \\
& \omega=\left(t_{\mathrm{s}}-12\right) \cdot 15^{\circ}
\end{aligned}
$$

In the above equations, $D_{\boldsymbol{H}, \boldsymbol{A}}$ is the distance between $\boldsymbol{H}$ and $\boldsymbol{A}$. Variables $\varphi, \delta, \omega$, and $t_{\mathrm{s}}$ are the latitude, declination, hour angle, and solar time, respectively; the heliostat azimuth in the field 
should be $2 \pi-\theta_{\mathrm{h}}$ when $y_{H, \mathrm{~g}}<0$; the solar azimuth should be $-A_{\mathrm{s}}$ when $\omega>0$.

\subsubsection{Solar model and photon initialization}

The shape effect of the sun is considered, and the photons initialized at a point on the heliostat are treated as a cone with an apex angle of $2 \delta_{\mathrm{sr}}=9.3 \mathrm{mrad}$ (Fig. 3)[51]. So, the unit vector (I) of an incident photon in $X_{\mathrm{i}} Y_{\mathrm{i}} Z_{\mathrm{i}}$ can be written in Eq.(9) [20]. A solar radiation model given in Eq.(11) is applied to predict the Direct Normal Irradiance $(D N I)$ at any time in a year [53]. The energy carried by each photon on the heliostats $\left(e_{\mathrm{p}}\right)$ is calculated by Eq.(12).

$$
\begin{gathered}
\boldsymbol{I}_{\mathrm{i}}=\left[\begin{array}{lll}
\delta_{\mathrm{s}} \cos \theta_{\mathrm{s}} & \delta_{\mathrm{s}} \sin \theta_{\mathrm{s}} & \sqrt{1-\delta_{\mathrm{s}}^{2}}
\end{array}\right]^{\mathrm{T}} \\
\delta_{\mathrm{s}}=\sin ^{-1}\left(\sqrt{\xi_{1} \sin ^{2} \delta_{\mathrm{sr}}}\right), \theta_{\mathrm{s}}=2 \pi \xi_{2} \\
D N I=1367\left[1+0.033 \cos \left(\frac{2 N_{\mathrm{day}} \pi}{365}\right)\right] \cdot \frac{\sin \alpha_{\mathrm{s}}}{\sin \alpha_{\mathrm{s}}+0.33} \\
e_{\mathrm{p}}=D N I \cdot L_{\mathrm{h}} W_{\mathrm{h}} \sum_{i=1}^{n_{\mathrm{h}}} \eta_{\mathrm{cos}}(i) / N_{\mathrm{p}}
\end{gathered}
$$

where each $\xi$ is a uniform random number between 0 and 1, i.e. $\xi \sim U[0,1] ; N_{\text {day }}$ is the day number in a year; $\eta_{\cos }(i)$ is the cosine efficiency of the $i$ th heliostat; $N_{\mathrm{p}}$ is the total number of the photons traced in the field; $L_{\mathrm{h}}$ and $W_{\mathrm{h}}$ are the height and width of the heliostat, respectively.

The solar radiation is assumed to be uniform, so the photons are initialized uniformly on the heliostat, and the intersection of the photon and the heliostat is initialized by Eq.(13).

$$
\boldsymbol{P}_{\mathrm{h}}=\left[\begin{array}{c}
x_{P, \mathrm{~h}} \\
y_{P, \mathrm{~h}} \\
z_{P, \mathrm{~h}}
\end{array}\right]=\left[\begin{array}{c}
W_{\mathrm{h}}\left(\xi_{3}-0.5\right) \\
L_{\mathrm{h}}\left(\xi_{4}-0.5\right) \\
2 D_{H, O}-\sqrt{4 D_{H, O}^{2}-x_{P, \mathrm{~h}}^{2}-y_{P, \mathrm{~h}}^{2}}
\end{array}\right]
$$

where $D_{\boldsymbol{H}, \boldsymbol{O}}$ is the distance between $\boldsymbol{H}$ and $\boldsymbol{O}$ in Fig. 3; and the heliostat radius equals to twice of $D_{H, \boldsymbol{O}}$.

\subsubsection{Specular reflection on the heliostat}

When the photon hits the heliostat, the reflection computation will be conducted. Firstly, a random number $\left(\xi_{5}\right)$ is generated to determine the optical process by Eq.(14). Then, if the photon is reflected, the incident vector $I_{\mathrm{i}}$ will be transformed from $X_{\mathrm{i}} Y_{\mathrm{i}} Z_{\mathrm{i}}$ to $X_{\mathrm{h}} Y_{\mathrm{h}} Z_{\mathrm{h}}$ by Eq.(15). Finally, the reflected vector $\boldsymbol{R}_{\mathrm{h}}$ at $\boldsymbol{P}_{\mathrm{h}}$ in $X_{\mathrm{h}} Y_{\mathrm{h}} Z_{\mathrm{h}}$ will be calculated by Eq. (16). The slope error is assumed to 
follow the Gaussian distribution[51], and the normal vector $\left(\boldsymbol{N}_{\mathrm{h}}\right)$ at $\boldsymbol{P}_{\mathrm{h}}$ is expressed in Eq.(17). The realistic normal vector for each location on the heliostat can also be used to replace $\boldsymbol{N}_{\mathrm{h}}$ for more accurate simulation if the measured data are obtained using the approach given in Ref.[54].

$$
\left\{\begin{array}{l}
0 \leq \xi_{5}<\rho_{\mathrm{h}, 1} \cdot \rho_{\mathrm{h}, 2} \cdot \eta_{\mathrm{att}}, \text { specular reflection } \\
\rho_{\mathrm{h}, 1} \cdot \rho_{\mathrm{h}, 2} \cdot \eta_{\mathrm{att}} \leq \xi_{5} \leq 1, \text { abandoned }
\end{array}\right.
$$

$$
\boldsymbol{I}_{\mathrm{h}}=\left[\cos \alpha_{\mathrm{hi}} \cos \beta_{\mathrm{hi}} \cos \gamma_{\mathrm{hi}}\right]^{\mathrm{T}}=\boldsymbol{M}_{4} \boldsymbol{M}_{3} \boldsymbol{M}_{2} \boldsymbol{M}_{1} \cdot \boldsymbol{I}_{\mathrm{i}}
$$

$$
\rho_{\mathrm{h}}=\sqrt{-2 \sigma_{\mathrm{se}}^{2} \ln \left(1-\xi_{6}\right)}, \varphi_{\mathrm{h}}=2 \pi \xi_{7}
$$

where $\eta_{\text {att }}$ is the atmospheric attenuation which is computed as a function of the distance between $\boldsymbol{O}$ and $\boldsymbol{H}$ for each heliostat[55]; $\boldsymbol{M}_{1}$ and $\boldsymbol{M}_{2}$ are the transformation matrixes from $X_{\mathrm{i}} Y_{\mathrm{i}} Z_{\mathrm{i}}$ to $X_{\mathrm{g}} Y_{\mathrm{g}} Z_{\mathrm{g}} ; \boldsymbol{M}_{3}$ and $\boldsymbol{M}_{4}$ are the transformation matrixes from $X_{\mathrm{g}} Y_{\mathrm{g}} Z_{\mathrm{g}}$ to $X_{\mathrm{h}} Y_{\mathrm{h}} Z_{\mathrm{h}} ; \boldsymbol{M}_{5}$ and $\boldsymbol{M}_{6}$ are the transformation matrixes to introduce slope error [56]; $\rho \mathrm{h}$ and $\varphi \mathrm{h}$ are the radial and tangential angles of $N_{\mathrm{h}}$ caused by slope error [51].

\subsubsection{Shading and blocking}

The shading is the part of heliostat shadowed by the adjacent heliostats or the tower, and the blocking is the part of reflected rays blocked by nearby heliostats (Fig. 3). The blocking here is taken as an example to illustrate the modeling of the two processes. First, the initialized location $\left(\boldsymbol{P}_{\mathrm{I}}\right)$ on heliostat I and the reflection vector $\left(\boldsymbol{R}_{\mathrm{I}}\right)$ at $\boldsymbol{P}_{\mathrm{I}}$ are transformed from $X_{\mathrm{h}} Y_{\mathrm{h}} Z_{\mathrm{h}}(\mathrm{I})$ to $X_{\mathrm{h}} Y_{\mathrm{h}} Z_{\mathrm{h}}(\mathrm{II})$ and expressed as $\boldsymbol{P}_{\mathrm{I}, \mathrm{II}}$ (Eq.(18)) and $\boldsymbol{R}_{\mathrm{I}, \mathrm{II}}$ (Eq. (19)), respectively. Then, the equation of the reflected ray in system II can be derived using $\boldsymbol{P}_{\mathrm{I}, \mathrm{II}}$ and $\boldsymbol{R}_{\mathrm{I}, \mathrm{II}}$. Finally, the intersection of the ray and heliostat II surface is calculated, and if it is within heliostat II, the ray is blocked.

$$
\begin{gathered}
\boldsymbol{P}_{\mathrm{I}, \mathrm{II}}=\left(\boldsymbol{M}_{4} \boldsymbol{M}_{3}\right)_{\mathrm{II}} \cdot\left[\left(\boldsymbol{M}_{8} \boldsymbol{M}_{7}\right)_{\mathrm{I}} \cdot \boldsymbol{P}_{\mathrm{I}}+\boldsymbol{H}_{\mathrm{I}}-\boldsymbol{H}_{\mathrm{II}}\right] \\
\boldsymbol{R}_{\mathrm{I}, \mathrm{II}}=\left(\boldsymbol{M}_{4} \boldsymbol{M}_{3}\right)_{\mathrm{II}} \cdot\left(\boldsymbol{M}_{8} \boldsymbol{M}_{7}\right)_{\mathrm{I}} \cdot \boldsymbol{R}_{\mathrm{I}}
\end{gathered}
$$

where $\boldsymbol{M}_{7}$ and $\boldsymbol{M}_{8}$ are the transformation matrixes from $X_{\mathrm{h}} Y_{\mathrm{h}} Z_{\mathrm{h}}$ to $X_{\mathrm{g}} Y_{\mathrm{g}} Z_{\mathrm{g}}$.

\subsection{Modeling of solar ray transfer in the MTCR}

\subsubsection{Intersection with the surfaces in MTCR}

When a ray is reflected and arrives at the focal plane of the field, i.e., the MTCR's aperture (Fig. 
3), the intersection $\boldsymbol{P}_{\mathrm{a}, \mathrm{r}}$ in $X_{\mathrm{r}} Y_{\mathrm{r}} Z_{\mathrm{r}}$ is calculated by transforming $\boldsymbol{P}_{\mathrm{h}}$ and $\boldsymbol{R}_{\mathrm{h}}$ to $X_{\mathrm{r}} Y_{\mathrm{r}} Z_{\mathrm{r}}$, which are expressed as $\boldsymbol{P}_{\mathrm{h}, \mathrm{r}}$ and $\boldsymbol{R}_{\mathrm{r}}$ in Eq.(20) and Eq.(21), respectively. When the ray gets through the aperture and hits the tube or wall, the intersection will be calculated, where the particular orientation of each surface has been considered. The intersection with the tube is taken as an example to illustrate this process. Firstly, the $\boldsymbol{P}_{\mathrm{a}, \mathrm{r}}$ and $\boldsymbol{R}_{\mathrm{r}}$ are transformed from $X_{\mathrm{r}} Y_{\mathrm{r}} Z_{\mathrm{r}}$ to $X_{\mathrm{t}} Y_{\mathrm{t}} Z_{\mathrm{t}}$ by Eq.(22) and Eq.(23) and expressed as $\boldsymbol{P}_{\mathrm{a}, \mathrm{t}}$ and $\boldsymbol{I}_{\mathrm{t}}$, respectively. Then, the intersection $\left(\boldsymbol{P}_{\mathrm{t}, \mathrm{t}}=\left[\begin{array}{ll}x_{P, \mathrm{t}} & y_{\boldsymbol{P}, \mathrm{t}} \\ z_{P, \mathrm{t}}\end{array}\right]^{\mathrm{T}}\right)$ in $X_{\mathrm{t}} Y_{\mathrm{t}} Z_{\mathrm{t}}$ is computed by solving the ray and the tube equations. The intersection of the ray and the wall can be calculated in the similar way.

\subsubsection{Multiple reflections among the tubes and walls}

When the photon hits the cavity walls or the tubes (Fig. 3 ), a random number $\left(\xi_{8}\right)$ is generated to determine the optical process by Eq.(24). If the photon is reflected diffusely, the reflected vector $\left(\boldsymbol{R}_{1}\right)$ in $X_{1} Y_{1} Z_{1}$ will be computed by Eq. (25) based on the Lambert law [20, 57]. If the photon is reflected specularly, $\boldsymbol{R}_{1}$ will be calculated by Fresnel's Law in the similar way as that on the heliostat $[20,58]$.

where $\boldsymbol{O}_{\mathrm{g}}$ is the origin of $X_{\mathrm{r}} Y_{\mathrm{r}} Z_{\mathrm{r}}$ in $X_{\mathrm{g}} Y_{\mathrm{g}} Z_{\mathrm{g}} ; \boldsymbol{M}_{9}$ is the transformation matrix from $X_{\mathrm{g}} Y_{\mathrm{g}} Z_{\mathrm{g}}$ to $X_{\mathrm{r}} Y_{\mathrm{r}} Z_{\mathrm{r}}$; $\boldsymbol{M}_{10}$ and $\boldsymbol{M}_{11}$ are the transformation matrixes from $X_{\mathrm{r}} Y_{\mathrm{r}} Z_{\mathrm{r}}$ to $X_{\mathrm{t}} Y_{\mathrm{t}} Z_{\mathrm{t}} ; \boldsymbol{T}_{\mathrm{r}}$ is the origin of $X_{\mathrm{t}} Y_{\mathrm{t}} Z_{\mathrm{t}}$ in $X_{\mathrm{r}} Y_{\mathrm{r}} Z_{\mathrm{r}}$.

$$
\begin{gathered}
\boldsymbol{P}_{\mathrm{h}, \mathrm{r}}=\boldsymbol{M}_{9} \cdot\left(\boldsymbol{M}_{8} \boldsymbol{M}_{7} \cdot \boldsymbol{P}_{\mathrm{h}}+\boldsymbol{H}_{\mathrm{g}}-\boldsymbol{O}_{\mathrm{g}}\right) \\
\boldsymbol{R}_{\mathrm{r}}=\boldsymbol{M}_{9} \boldsymbol{M}_{8} \boldsymbol{M}_{7} \cdot \boldsymbol{R}_{\mathrm{h}} \\
\boldsymbol{P}_{\mathrm{a}, \mathrm{t}}=\boldsymbol{M}_{11} \boldsymbol{M}_{10} \cdot\left(\boldsymbol{P}_{\mathrm{a}, \mathrm{r}}-\boldsymbol{T}_{\mathrm{r}}\right) \\
\boldsymbol{I}_{\mathrm{t}}=\boldsymbol{M}_{11} \boldsymbol{M}_{10} \cdot \boldsymbol{R}_{\mathrm{r}}
\end{gathered}
$$


intersection between the ray and other surfaces using the new $\boldsymbol{R}_{\mathrm{r}}$ and $\boldsymbol{P}_{\mathrm{t}, \mathrm{r} \text {. These processes will }}$ continue until the ray is absorbed or lost.

$$
\boldsymbol{R}_{\mathrm{t}}=\boldsymbol{M}_{12} \cdot \boldsymbol{R}_{1}, \boldsymbol{R}_{\mathrm{r}}=\boldsymbol{M}_{14} \boldsymbol{M}_{13} \cdot \boldsymbol{R}_{\mathrm{t}}
$$

$$
\boldsymbol{P}_{\mathrm{t}, \mathrm{r}}=\boldsymbol{M}_{14} \boldsymbol{M}_{13} \cdot \boldsymbol{P}_{\mathrm{t}, \mathrm{t}}+\boldsymbol{T}_{\mathrm{r}}
$$

where $\boldsymbol{P}_{\mathrm{t}, \mathrm{t}}=\left[\begin{array}{lll}x_{\boldsymbol{P}, \mathrm{t}} & y_{\boldsymbol{P}, \mathrm{t}} & z_{\boldsymbol{P}, \mathrm{t}}\end{array}\right]^{\mathrm{T}}$ is the intersection on the tube in $X_{\mathrm{t}} Y_{\mathrm{t}} Z_{\mathrm{t}} ; \boldsymbol{M}_{12}$ is the transformation matrix from $X_{1} Y_{\mathrm{l}} Z_{\mathrm{l}}$ to $X_{\mathrm{t}} Y_{\mathrm{t}} Z_{\mathrm{t}} ; \boldsymbol{M}_{13}$ and $\mathbf{M}_{14}$ are the transformation matrixes from $X_{\mathrm{t}} Y_{\mathrm{t}} Z_{\mathrm{t}}$ to $X_{\mathrm{r}} Y_{\mathrm{r}} Z_{\mathrm{r}}$.

\subsubsection{Statistics of the photon and flux}

The quadrilateral grids are generated on the tubes and walls, and when a photon is absorbed by these surfaces, the statistics of the photon would be conducted in the following way. First, the photons absorbed in each element $\left(n_{\mathrm{p}, \mathrm{e}}\right)$ would be counted. Then, the local solar flux in each element ( $\left.q_{1}\right)$ would be computed after the tracing of the last photon by Eq.(28).

$$
q_{1}=e_{\mathrm{p}} n_{\mathrm{p}, \mathrm{e}} / S_{\mathrm{e}}
$$

where $S_{\mathrm{e}}$ is the area of the element.

\subsection{Parameter definitions}

Some performance indexes are defined below to characterize the optical performance.

The instantaneous efficiency of the $\operatorname{MTCR}\left(\eta_{i, R}\right)$ which is also called the effective absorptivity is defined as the ratio of the energy absorbed by the tubes $\left(Q_{i j, \mathrm{~T}}\right)$ and the energy entering the aperture $\left(Q_{i j, \mathrm{~A}}\right)$ in Eq.(29). The instantaneous optical loss $\left(Q_{\mathrm{i}, \text { loss }}\right)$ of the MTCR is defined as the difference between $Q_{i j, \mathrm{~A}}$ and $Q_{i j, \mathrm{~T}}$ in Eq.(29). One important advantage of the MTCR is reducing optical loss due to the cavity effect compared to the Multi-tube External Receiver (MTER). The impact of cavity effect is quantitated in the following way. When the cavity effect is considered, $Q_{i j, \mathrm{~T}}$ will be calculated by considering the multiple reflections and absorptions for each ray on the tubes and walls. When the cavity effect is not considered, $Q_{i j, \mathrm{~T}}$ will be calculated by assuming that each incident ray from the field will just interact with the tube or wall one time. After this only interaction (absorption or reflection), the ray which is not absorbed will be abandoned, and this is similar to what happens in a MTER.

The energy maldistribution index $(\sigma \mathrm{E})$ among the tubes is defined in Eq.(30). The instantaneous optical efficiency of the SPT $\left(\eta_{\mathrm{i}, \mathrm{T}}\right)$ is defined as the ratio of $Q_{i j, \mathrm{~T}}$ and the maximum solar energy that 
can be accepted by the heliostats $\left(Q_{i j, \mathrm{H}}\right)$ in Eq.(31). The daily and yearly optical efficiencies are defined as $\eta_{\mathrm{d}, \mathrm{T}}$ and $\eta_{\mathrm{y}, \mathrm{T}}$ in the similar way in Eq.(32) and Eq.(33), where the SPT is assumed to operate when the solar altitude is larger than $10^{\circ}[20]$. The instantaneous optical efficiency $(\eta \mathrm{i}, \mathrm{A})$ for $Q_{i j, \mathrm{~A}}$ is defined as the ratio of $Q_{i j, \mathrm{~A}}$ and $Q_{i j, \mathrm{H}}$ in Eq.(35), and the daily and yearly efficiencies of the energy entering the aperture are defined in the similar way.

\section{Grid-independence study, uncertainty analysis, and validation of the model}

The grid-independence test is conducted using five grid systems at summer solstice noon, where Model B and the one-point aiming strategy are applied, and sufficient photons of $3 \times 10^{9}$ are traced. The result is given in Fig. 6, where the local flux at $Y_{\mathrm{t}}=0$ on Tube 443 located at the hot spot is examined. It is found that the flux profile varies insignificantly when the grid system is larger than 20 (circumferential) $\times 200$ (lengthwise) for each tube, which indicates this grid system can be regarded as grid-independent.

The uncertainty which depends on photon number $\left(N_{\mathrm{p}}\right)$ is analyzed with at the above condition. Figure 7 shows the maximum flux on the tubes $\left(q_{1, \max }\right)$ and $\eta_{\mathrm{i}, \mathrm{T}}$ with different $N_{\mathrm{p}}$. It is seen that there will be no obvious change in $q 1$, max and $\eta_{\mathrm{i}, \mathrm{T}}$ when $N_{\mathrm{p}}$ is larger than $5 \times 10^{8}$ and $2 \times 10^{7}$, respectively. 


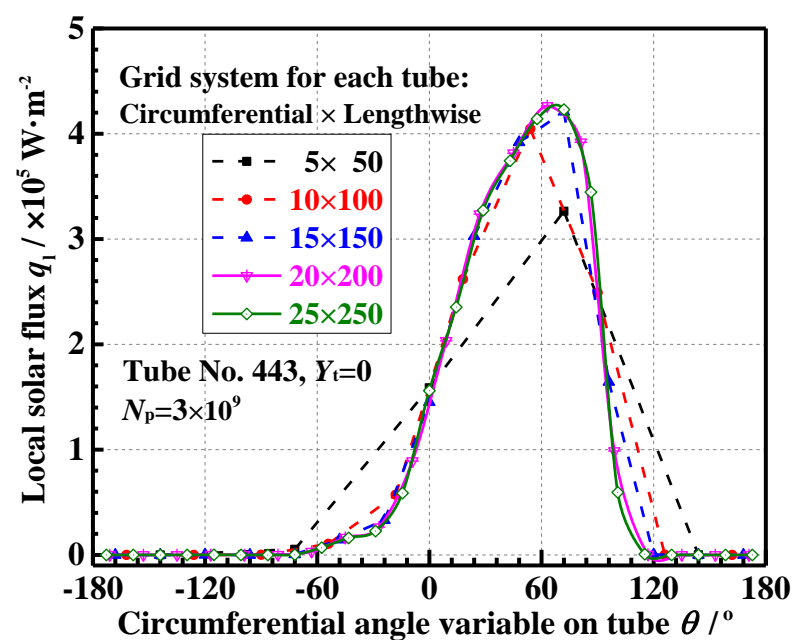

Fig. 6. Grid-independence test.

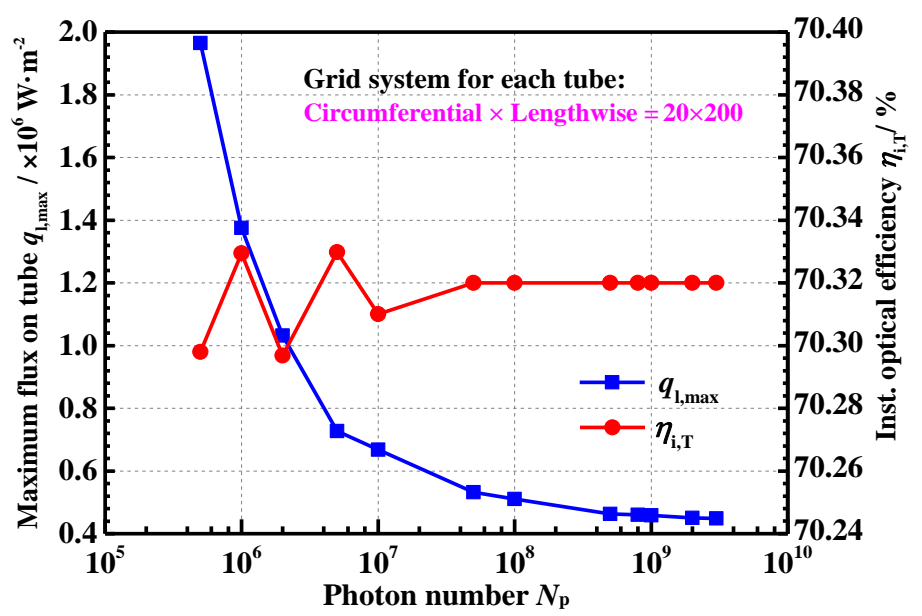

Fig. 7. Uncertainty analysis of the MCRT model

To validate the model, firstly, the flux contour for a single heliostat located at $(-189.3,-110.9)$ in Fig. 1(b) was computed using both present model and SolTrace under the above condition. It is seen in Fig. 8 that the computed quasi-circular contours on the MTCR's aperture agree well with each other. Then, the computed incident flux and power on the MTCR's tube panels (simplified as flat plates) of PS10 plant is compared with those in literature [37] as shown in Fig. 9, where 624 heliostats are used in the heliostat field. It is seen that the patterns of the fluxes in Fig. 7(a) and 7(b) agree well with each other. The deviations of the peak fluxes and the total powers are less than $0.1 \%$ and $0.4 \%$, respectively. Furthermore, the flux profiles on a MTCR's tubes in a linear Fresnel reflector [20] were computed and compared with those of SOLTRACE at normal incidence. It is seen in Fig. 10 that the present profiles agree with those of SOLTRACE quite well. The good 
agreement indicates that the present model is appropriate for modeling both the heliostat field and the MTCR.

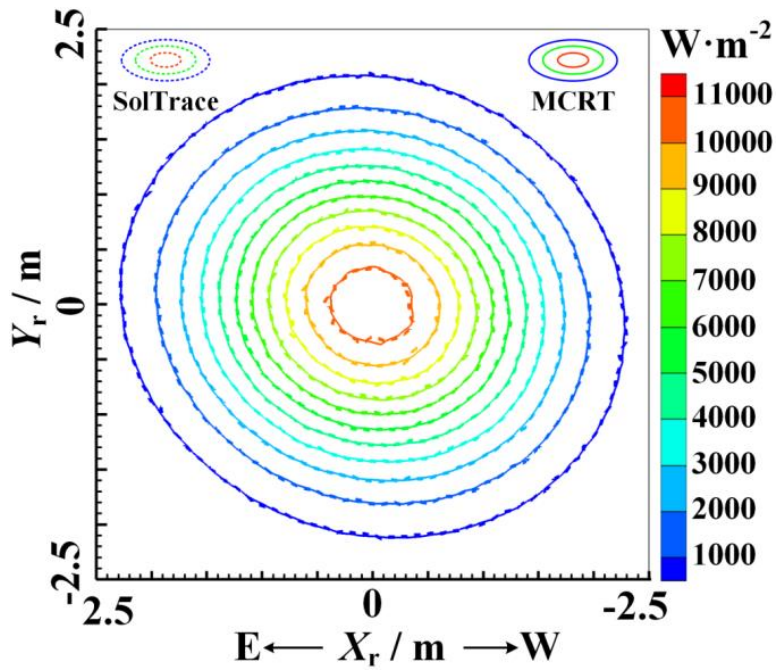

Fig. 8. Comparison of the incident flux contours for a single heliostat between MCRT and SOLTRACE.

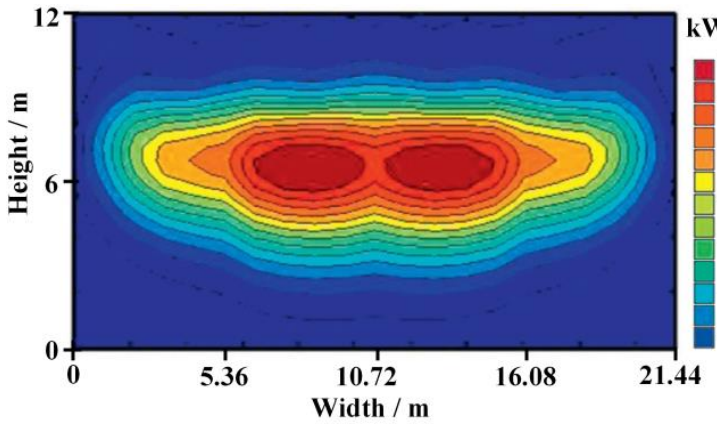

(a) Data from Ref.[37]. Total Power $=54.8$ MW, Peak flux $=714.0 \mathrm{~kW} \cdot \mathrm{m}^{-2}$

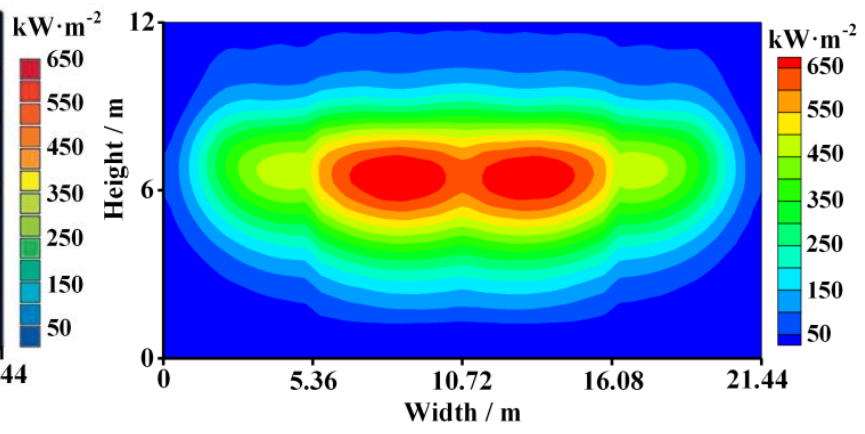

(b) Present result. Total Power $=55.0$ MW, Peak flux $=714.9 \mathrm{~kW} \cdot \mathrm{m}^{-2}$

Fig. 9. Comparison of the incident flux contours for PS10 plant between published data and present result (Equinox noon, $D N I=970 \mathrm{~W} \cdot \mathrm{m}^{-2}$ ).

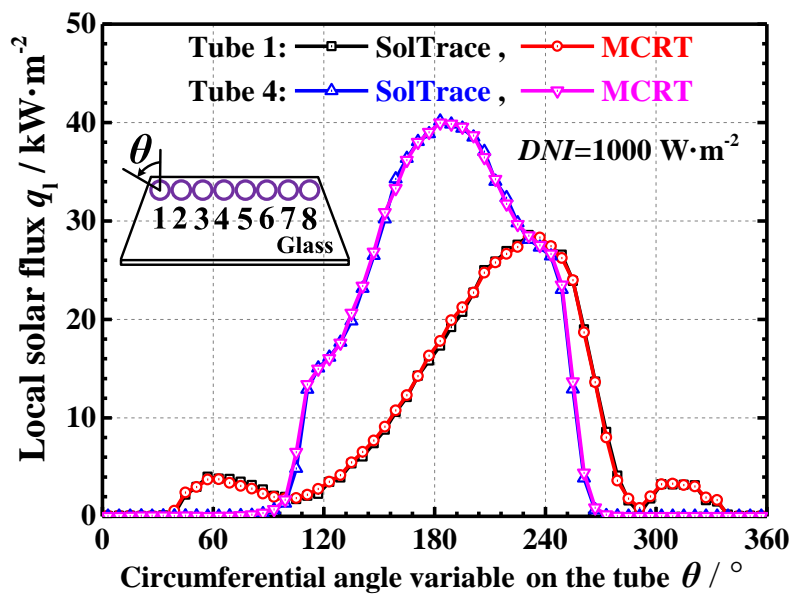

Fig. 10. Comparison of the flux profiles on the tubes between MCRT and SOLTRACE. 


\section{Results and discussion}

In this section, the characterization of the real-time optical performance for the DAHAN plant is illustrated as an example to show the application of the present MCRT model. Firstly, the detailed real-time flux distribution in the MTCR is studied. Then, the effects of tracking models and aiming strategies on both the real-time flux and the real-time optical efficiency are investigated. Then, the real-time optical efficiency at different time in a year is discussed. Finally, the impact of the cavity effect and absorptivity on the efficiency is further analyzed.

\subsection{Typical real-time solar flux distribution}

Figure 11 shows the typical solar fluxes in the MTCR at $t_{\mathrm{s}}=12$, spring equinox, where the one-point aiming strategy and Model B are used. It is seen from Fig. 11(a) that local flux on the aperture decreases from the center to the margin because all heliostats aim at the center, and the maximum flux $\left(q_{1, \max }\right)$ of $2.622 \times 10^{6} \mathrm{~W} \cdot \mathrm{m}^{-2}$ appears at the center. From Fig. $11(\mathrm{~b})$ and (c), it is observed that two high flux regions appear on (1) the west panels and (3) the east panels, where $q_{1, \max }$ of $5.141 \times 10^{5} \mathrm{~W} \cdot \mathrm{m}^{-2}$ occurs on tube 443 in Fig. 2 and Fig. 11(c). This is because most energy from the heliostats at the west side of the field will be concentrated on the east panels after crossing the aperture center, and the opposite is true for the heliostats at the east side. It is also seen that most energy is concentrated on the middle part of each tube, and other parts along the length are barely utilized. This is because the rays can only shine on the middle part of the tubes when all heliostats aim at the aperture center.

From Fig. 11(d), it is seen that a hot spot appears on the middle cavity wall defined in Fig. 2, because the incident rays from the field hit this wall through the gaps between the tubes. However, there is no spot on the east and west walls for the reason that the incident rays are blocked by the tubes installed along these walls which are very steep in the depth direction of the receiver. Also, two hot spots appear on the upper and lower walls due to the diffuse reflections in the MTCR. Figure 11 (e) illustrates the whole flux distribution in the MTCR combining the tubes and cavity walls, and this detailed distribution could be applied in heat transfer analysis of the MTCR and performance evaluation of the system in the future. 


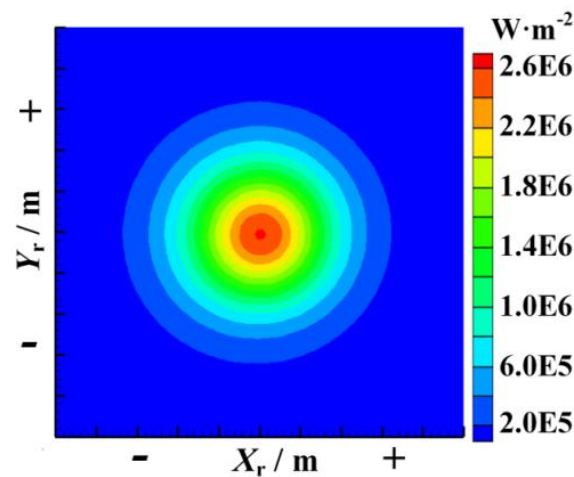

(a) Aperture, $\eta_{\mathrm{i}, \mathrm{A}}=80.7 \%, q_{1, \max }=2.622 \times 10^{6} \mathrm{~W} \cdot \mathrm{m}^{-2}$

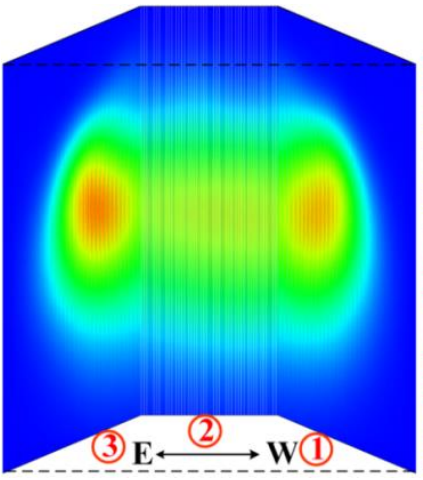

(b) Tubes, $\eta_{\mathrm{i}, \mathrm{T}}=75.7 \%, \sigma_{\mathrm{E}}=65.2 \%$
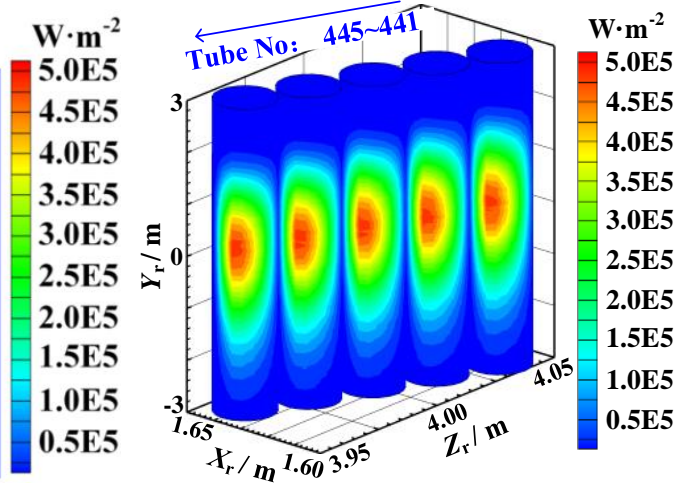

(c) $q_{1, \text { max }}=5.141 \times 10^{5} \mathrm{~W} \cdot \mathrm{m}^{-2}$, and $q_{1, \max }$ locates on tube 443 .

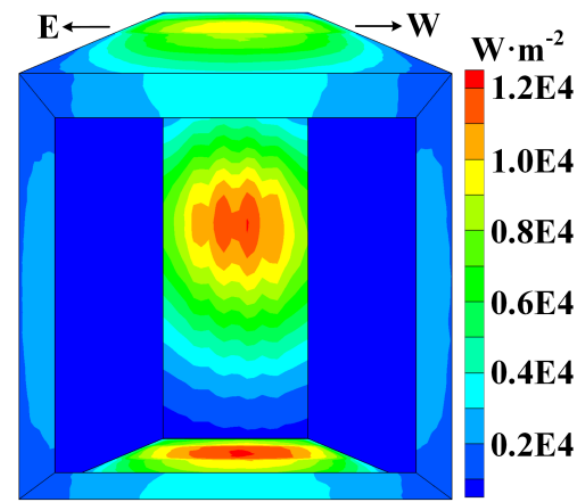

(d) Cavity walls, $q_{1, \max }=12710 \mathrm{~W} \cdot \mathrm{m}^{-2}$.

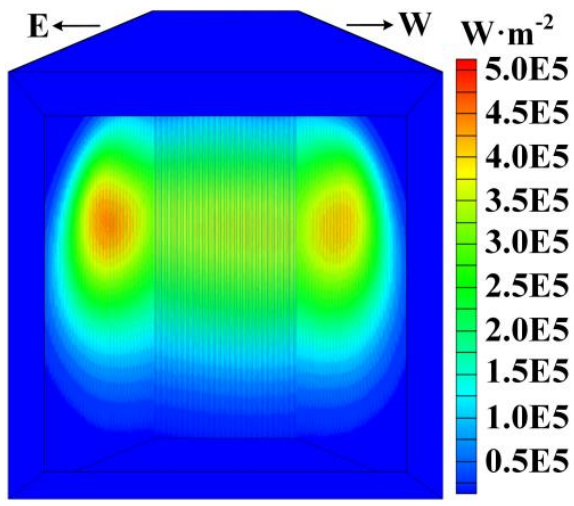

(e) The tubes and cavity walls.

Fig. 11. Typical solar flux distributions in the MTCR at $t_{\mathrm{s}}=12$, spring equinox (Model A, one-point aiming strategy, $\sigma_{\mathrm{te}}=0.46 \mathrm{mrad}, D N I=961 \mathrm{~W} \cdot \mathrm{m}^{-2}$ ).

\subsection{Effects of tracking-error models on real-time performance}

The effects of two tracking-error models on the real-time performance are studied in this section, where the one-point aiming strategy is used. The results of the solar flux distribution, maximum flux $\left(q_{1, \max }\right)$, maldistribution index $(\sigma \mathrm{E})$, and instantaneous efficiencies $\left(\eta_{\mathrm{i}, \mathrm{A}}, \eta_{\mathrm{i}, \mathrm{T}}\right)$ are compared.

Figure 11 and 12 show the solar fluxes computed using two tracking-error models with $\sigma$ te $=0.46 \mathrm{mrad}$. It is seen that the variation of the flux distribution is insignificant. And the values of $q_{1, \max }$ on the aperture and the tube for Model A are only about $5.8 \%$ and $2.5 \%$ larger than those for Model $\mathrm{B}$, respectively. It is also seen that the variations of $\sigma \mathrm{E}, \eta_{\mathrm{i}, \mathrm{A}}$ and $\eta_{\mathrm{i}, \mathrm{T}}$ are also not obvious. 


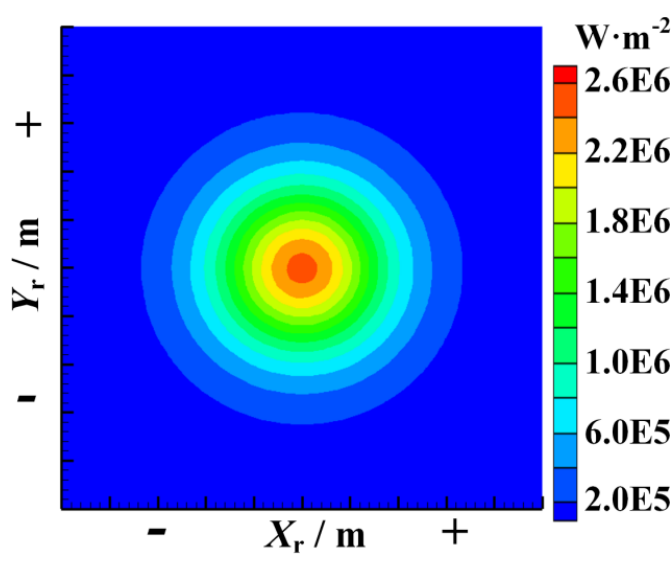

(a) Aperture

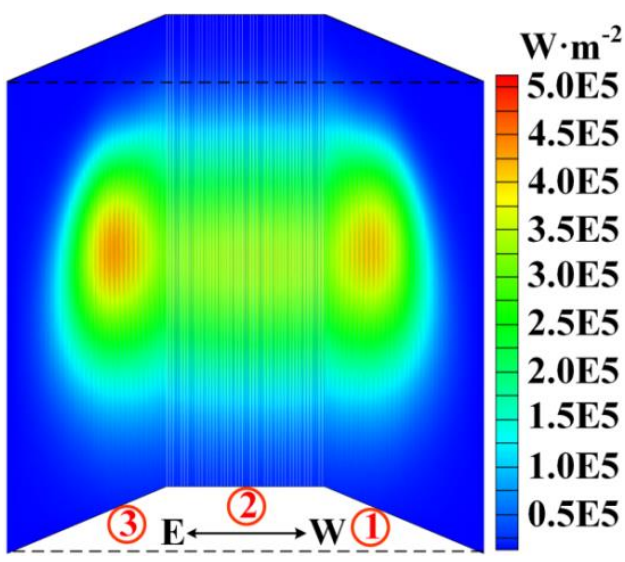

(b) Tubes

$$
q_{1, \max }=2.478 \times 10^{6} \mathrm{~W} \cdot \mathrm{m}^{-2}, \eta_{\mathrm{i}, \mathrm{A}}=80.5 \%
$$

$$
q_{1, \max }=5.016 \times 10^{5} \mathrm{~W} \cdot \mathrm{m}^{-2}, \eta_{\mathrm{i}, \mathrm{T}}=75.4 \%, \sigma_{\mathrm{E}}=63.5 \%
$$

Fig. 12. Solar fluxes on the aperture and tubes with Model B and $\sigma_{\mathrm{te}}=0.46 \mathrm{mrad}$ $\left(t_{\mathrm{s}}=12\right.$, spring equinox, $\left.D N I=961 \mathrm{~W} \cdot \mathrm{m}^{-2}\right)$.

Figure 13 and 14 show the solar fluxes computed using two tracking-error models with $\sigma_{\mathrm{te}}=1.0$ mrad. It is seen that the random effect on the flux distribution becomes significant for Model A. And the values of $q_{1, \max }$ on the aperture and the tube for Model A are $24.9 \%$ and $11.2 \%$ larger than those for Model B, respectively. It is also found that the maldistribution index $\left(\sigma_{\mathrm{E}}\right)$ for Model A is $8.2 \%$ larger than that for Model B. As a result, a deviation in $\eta_{\mathrm{i}, \mathrm{T}}$ of 1.5 percent is also observed.

These results indicate that the random effects of the tracking errors are smoothed by the widely-used Model B, which however is revealed by Model A more clearly. Since the accurate prediction of real-time optical performance is important for the safe operation and performance optimization of the plant, the random effect should be considered. For this purpose, Model A is recommended from the current study, especially, when $\sigma_{\text {te }}$ is relatively large.

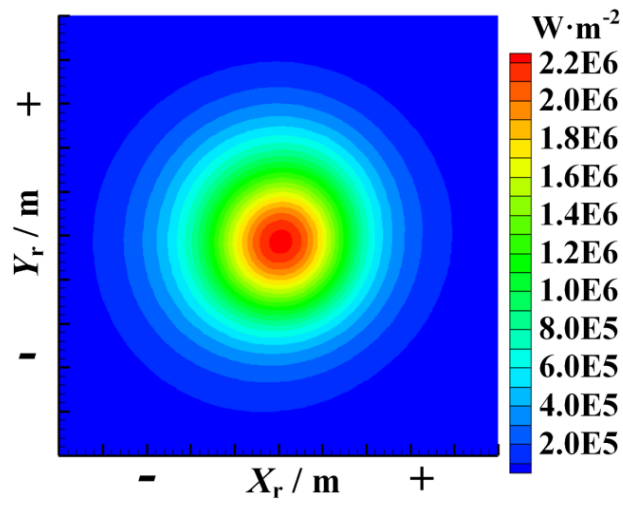

(a) Aperture $q_{1, \max }=2.254 \times 10^{6} \mathrm{~W} \cdot \mathrm{m}^{-2}, \eta_{\mathrm{i}, \mathrm{A}}=80.1 \%$

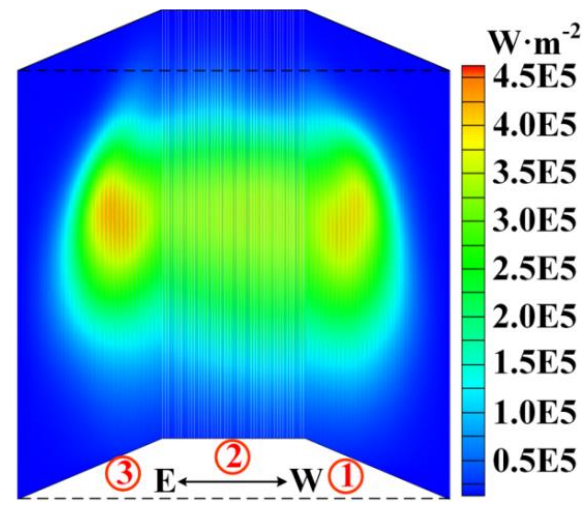

(b) Tubes

$q_{1, \max }=4.787 \times 10^{5} \mathrm{~W} \cdot \mathrm{m}^{-2}, \eta_{\mathrm{i}, \mathrm{T}}=75.0 \%, \sigma_{\mathrm{E}}=64.2 \%$

Fig. 13. Solar fluxes on the aperture and tubes with Model A and $\sigma_{\mathrm{te}}=1.00 \mathrm{mrad}$ 


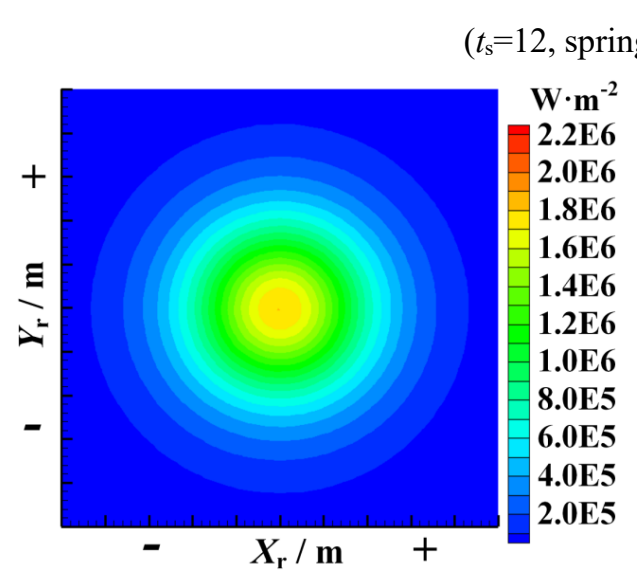

(a) Aperture

$$
q_{1, \max }=1.804 \times 10^{6} \mathrm{~W} \cdot \mathrm{m}^{-2}, \eta_{\mathrm{i}, \mathrm{A}}=78.6 \%
$$

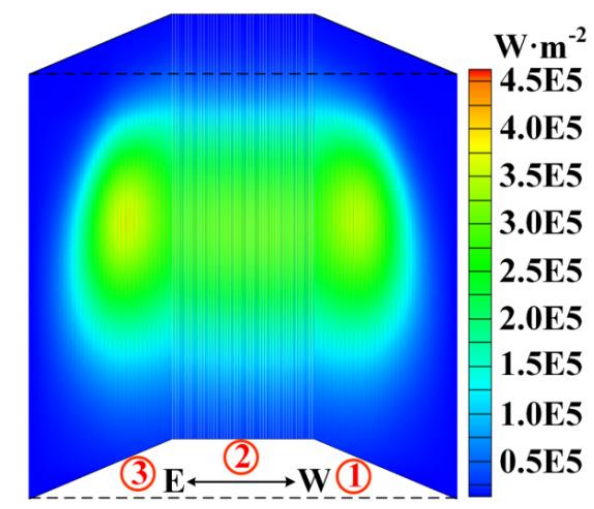

(b) Tubes

$q_{1, \max }=4.304 \times 10^{5} \mathrm{~W} \cdot \mathrm{m}^{-2}, \eta_{\mathrm{i}, \mathrm{T}}=73.5 \%, \sigma_{\mathrm{E}}=59.5 \%$
395

396

397

398

399

400

401

402

403

404

405

406

407

408

409

410

411

412

413

414

415

416

417

Fig. 14. Solar fluxes on the aperture and tubes with Model B and $\sigma_{\mathrm{te}}=1.00 \mathrm{mrad}$ $\left(t_{\mathrm{s}}=12\right.$, spring equinox, $\left.D N I=961 \mathrm{~W} \cdot \mathrm{m}^{-2}\right)$.

\subsection{Effects of aiming strategies on real-time performance}

The effects of one-point and multi-point aiming strategies on the real-time performance are investigated in this section. For DAHAN plant, a five-point aiming strategy as indicated in Fig. 1 and Fig. 2 is implemented, where the coordinate value $(d)$ for the aiming points in $X_{\mathrm{r}} Y_{\mathrm{r}} Z_{\mathrm{r}}$ is $0.7 \mathrm{~m}$.

Figure 11 and 15 show the solar fluxes obtained using the two aiming strategies at $t_{\mathrm{s}}=12$, spring equinox, and the fluxes at 15:00 are also illustrated in Fig. 16 and Fig. 17. It is seen that the maximum fluxes on the aperture and the tubes drop 36.8\% and $10.5 \%$ when the five-point strategy is applied at $t_{\mathrm{s}}=12$, respectively. And the corresponding values are $33.4 \%$ and $12.0 \%$ for $t_{\mathrm{s}}=15$, respectively. It is noteworthy that $q_{1, \max }$ on tubes decreases from $5.141 \times 10^{5} \mathrm{~W} \cdot \mathrm{m}^{-2}$ to $4.599 \times 10^{5}$ $\mathrm{W} \cdot \mathrm{m}^{-2}$ at $t_{\mathrm{s}}=12$. This sharp decline of $q_{1, \max }$ will certainly be of great help to the safe operation of the receiver.

Moreover, it is seen that the values of maldistribution index $(\sigma \mathrm{E})$ drop $31.6 \%$ and $33.7 \%$ when the five-point strategy is applied for $t_{\mathrm{s}}=12$ and $t_{\mathrm{s}}=15$, respectively, and it can also be seen that longer tubes are utilized. It indicates that the energy is distributed much more uniformly among the tubes, which could help to lower the average temperature and improve the thermal efficiency of the receiver. In addition, it is also found that the drops in the instantaneous optical efficiency for the power absorbed by tubes $\left(\eta_{\mathrm{i}, \mathrm{T}}\right)$ are just 1.0 percent and 1.2 percent for $t_{\mathrm{s}}=12$ and $t_{\mathrm{s}}=15$, respectively.

These results indicate that the fluxes in the MTCR can be greatly homogenized by the multi-point aiming strategy with just a little drop in optical efficiency. Therefore, this method should be recommended to study SPT and will be used in the following sections. Similar results have also been obtained by Binotti et al. [59] when the multi-point aiming strategy is applied in PS10 plant. 


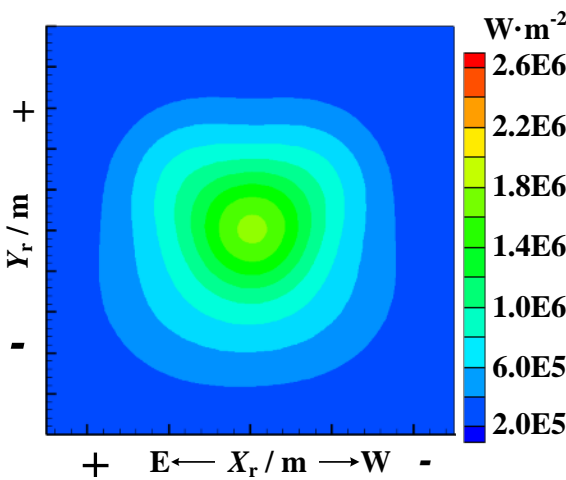

(a) Aperture,

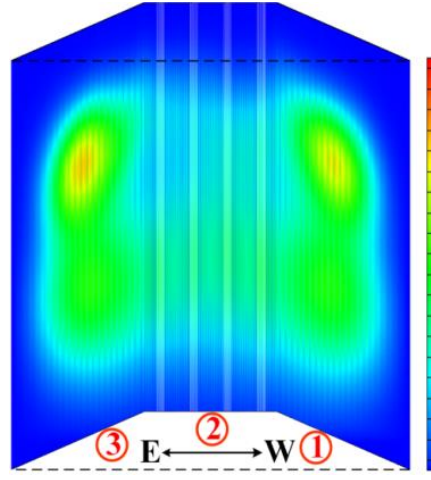

(b) Tubes,

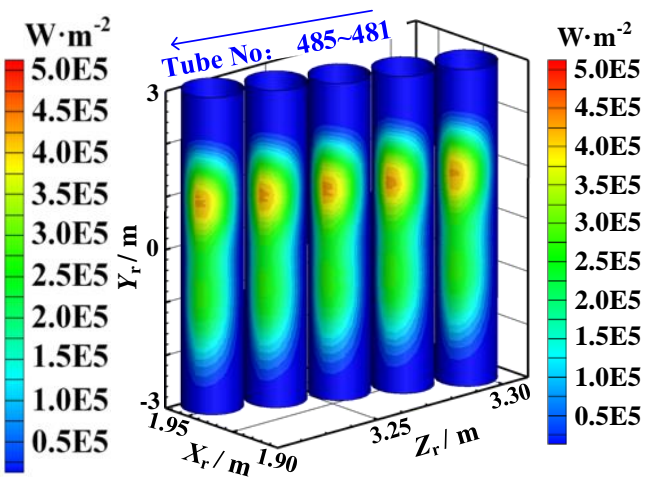

(c) $q_{1, \max }=4.599 \times 10^{5} \mathrm{~W} \cdot \mathrm{m}^{-2}$, and $q_{1, \max }$ locates on tube 482 . $\eta_{\mathrm{i}, \mathrm{A}}=80.0 \%, q_{1, \max }=1.656 \times 10^{6} \mathrm{~W} \cdot \mathrm{m}^{-2}$ $\eta_{\mathrm{i}, \mathrm{T}}=74.7 \%, \sigma_{\mathrm{E}}=44.6 \%$

Fig. 15. Solar flux distributions in the MTCR at $t_{\mathrm{s}}=12$, spring equinox (Multi-point aiming strategy, $\sigma_{\mathrm{te}}=0.46 \mathrm{mrad}, D N I=961 \mathrm{~W} \cdot \mathrm{m}^{-2}$ ).

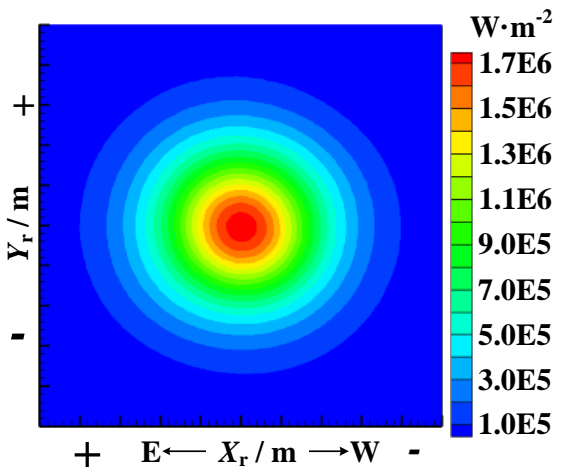

(a) Aperture,

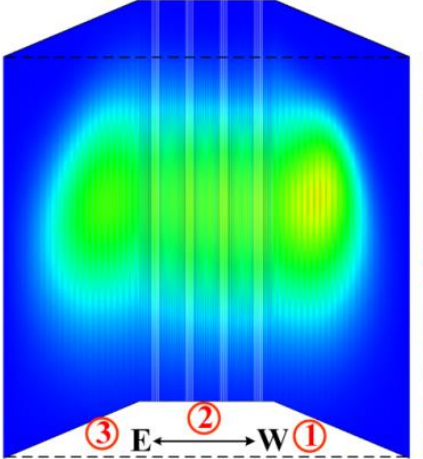

(b) Tubes,

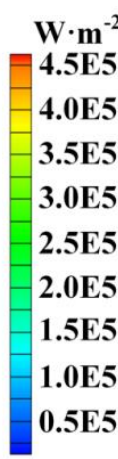

$\eta_{\mathrm{i}, \mathrm{T}}=69.5 \%, \sigma_{\mathrm{E}}=63.5 \%$

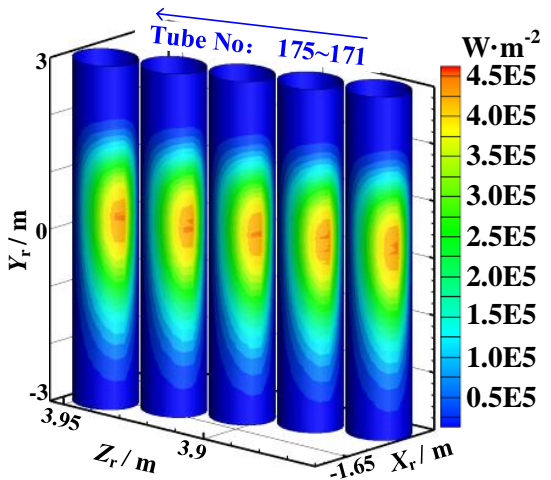

(c) $q_{1, \max }=4.320 \times 10^{5} \mathrm{~W} \cdot \mathrm{m}^{-2}$, and $q_{1, \max }$ locates on tube 175 . $\eta_{\mathrm{i}, \mathrm{A}}=74.1 \%, q_{1, \max }=1.770 \times 10^{6} \mathrm{~W} \cdot \mathrm{m}^{-2}$

Fig. 16. Solar flux distributions in the MTCR at $t_{\mathrm{s}}=15$, spring equinox

(One-point aiming strategy, $\sigma_{\mathrm{te}}=0.46 \mathrm{mrad}, D N I=855 \mathrm{~W} \cdot \mathrm{m}^{-2}$ ).

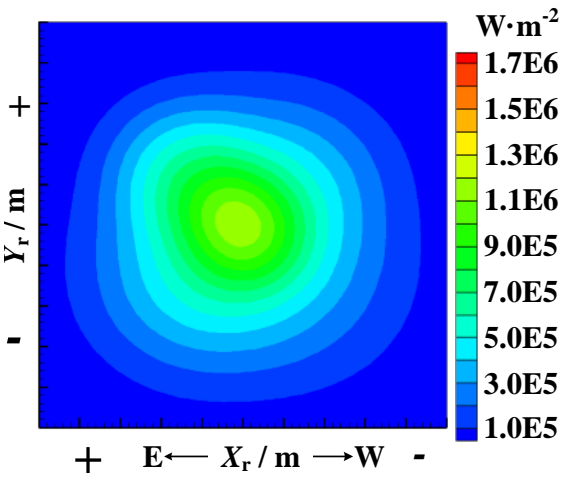

(a) Aperture,

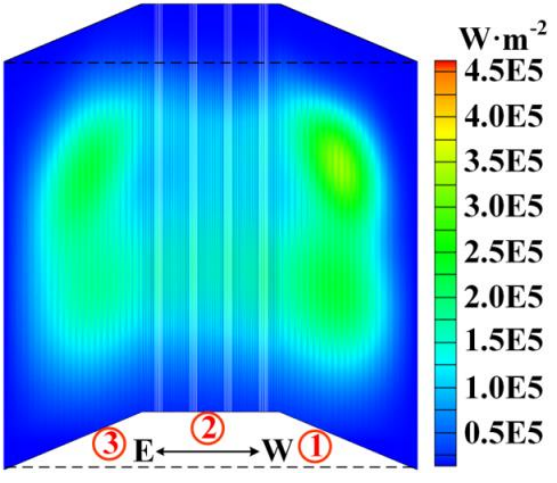

(b) Tubes,

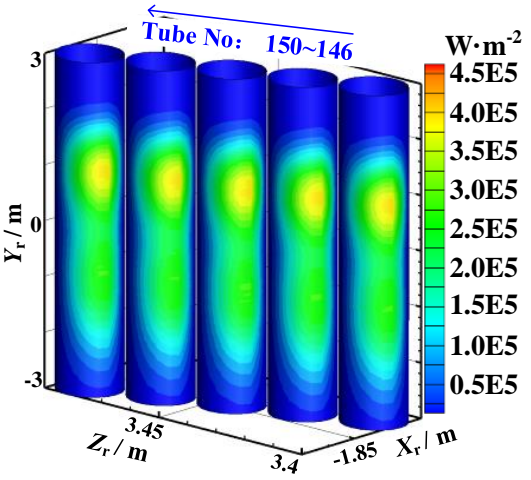

(c) $q_{1, \max }=3.799 \times 10^{5} \mathrm{~W} \cdot \mathrm{m}^{-2}$, and $q_{1, \max }$ locates on tube 147 . $\eta_{\mathrm{i}, \mathrm{A}}=73.0 \%, q_{1, \max }=1.179 \times 10^{6} \mathrm{~W} \cdot \mathrm{m}^{-2}$ $\eta_{\mathrm{i}, \mathrm{T}}=68.3 \%, \sigma_{\mathrm{E}}=42.1 \%$

Fig. 17. Solar flux distributions in the MTCR at $t_{\mathrm{s}}=15$, spring equinox (Multi-point aiming strategy, $\sigma_{\mathrm{te}}=0.46 \mathrm{mrad}, D N I=855 \mathrm{~W} \cdot \mathrm{m}^{-2}$ ).

\subsection{Real-time optical efficiency of the plant in a year}

The instantaneous efficiency of the plant for the power entering the aperture $\left(\eta_{\mathrm{i}, \mathrm{A}}\right)$, the 
instantaneous efficiency of the plant for the power absorbed by the tubes $\left(\eta_{\mathrm{i}, \mathrm{T}}\right)$ and the instantaneous efficiency / effective absorptivity of the $\operatorname{MTCR}\left(\eta_{\mathrm{i}, \mathrm{R}}\right)$ in a year are analyzed in this section.

Figure 18 and 19 illustrate the variations of $\eta_{\mathrm{i}, \mathrm{A}}, \eta_{\mathrm{i}, \mathrm{T}}$ and $\eta_{\mathrm{i}, \mathrm{R}}$ on three typical days which are the summer solstice, spring equinox and winter solstice. It is seen in Fig. 18 that the work time increases from the winter solstice to the summer solstice due to the variation of the sunshine duration. It is also observed that $\eta_{\mathrm{i}, \mathrm{A}}$ and $\eta_{\mathrm{i}, \mathrm{T}}$ increase in the morning and decrease in the afternoon in every day, and the $\eta_{\mathrm{i}, \mathrm{A}}$ of $80.0 \%$ and $\eta_{\mathrm{i}, \mathrm{T}}$ of $74.7 \%$ are achieved at the noon of spring equinox, which is the design point of the plant. It is seen in Fig. 19 that $\eta_{\mathrm{i}, \mathrm{R}}$ is around $93.5 \%$ for winter solstice and spring equinox, and for summer solstice it is around $93.0 \%$. It is also seen that $\eta_{\mathrm{i}, \mathrm{R}}$ almost keeps constant when $t_{\mathrm{s}}=9-15 \mathrm{~h}$, while it is smaller in the early morning and late afternoon. This is because a greater proportion of power is shined on the cavity walls under the later condition.

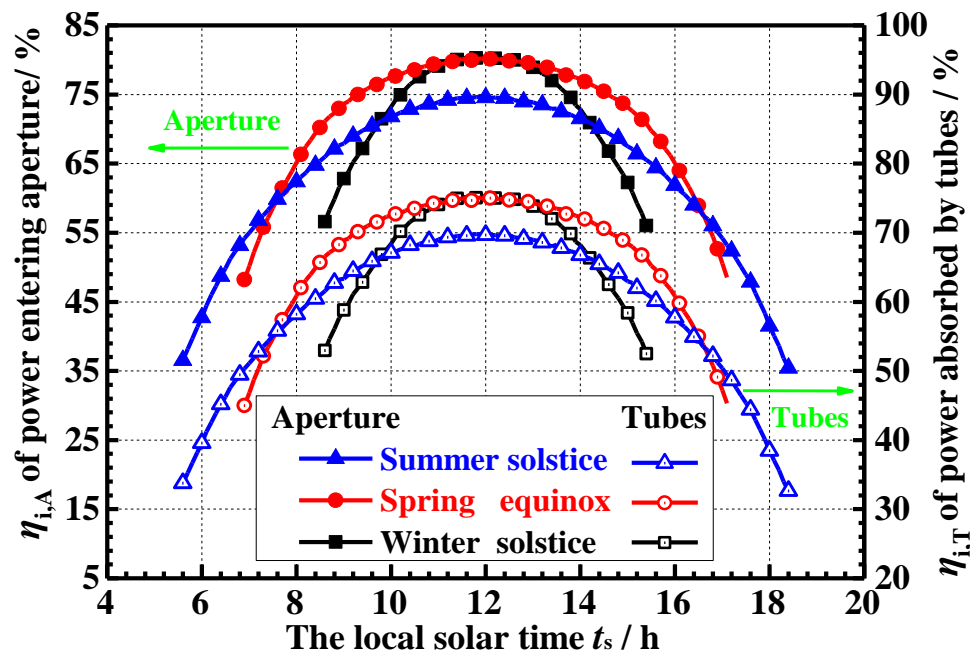

Fig. 18. Variations of $\eta_{\mathrm{i}, \mathrm{A}}$ and $\eta_{\mathrm{i}, \mathrm{T}}$ on three typical days.

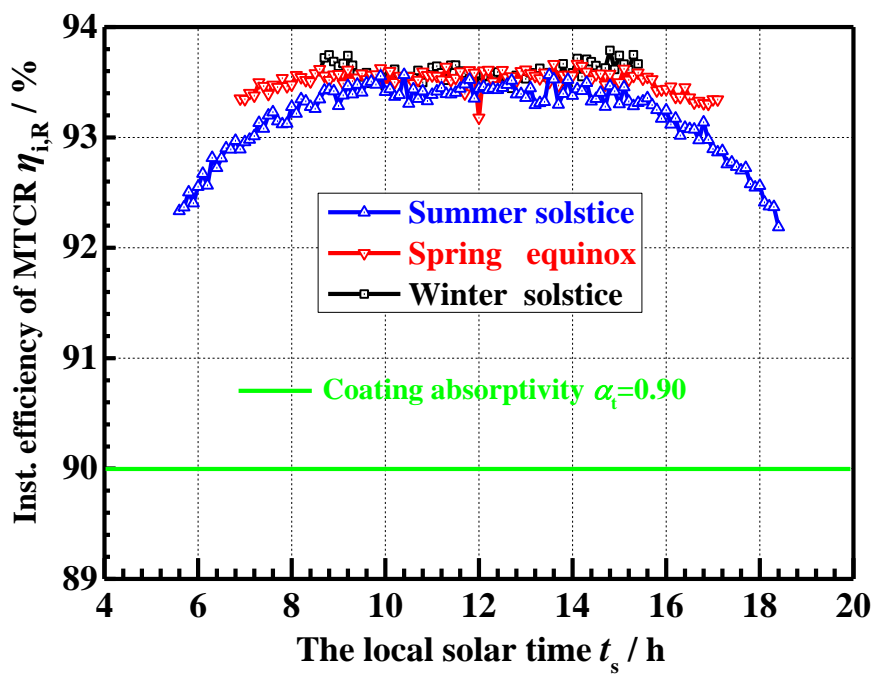

Fig. 19. Variation of $\eta_{\mathrm{i}, \mathrm{R}}$ on three typical days. 
Figure 20 shows the variations of $\eta_{\mathrm{i}, \mathrm{A}}, \eta_{\mathrm{i}, \mathrm{T}}$ and $\eta_{\mathrm{i}, \mathrm{R}}$ during the whole year. It is seen that a whole year can be divided into two ranges approximately. One is the low-efficiency range which appears in summer, the other is the high-efficiency range that ranges from autumn to the spring of next year. It can be found that $\eta_{\mathrm{i}, \mathrm{A}}$ and $\eta_{\mathrm{i}, \mathrm{T}}$ during a day within the low-efficiency range vary more violently than those within the high-efficiency range. This is because the work time in summer is much longer than that in other seasons, so the efficiencies in the early morning and late afternoon are quite low as shown in Fig. 18. Furthermore, it is observed that the effective absorptivity of the MTCR $\left(\eta_{\mathrm{i}, \mathrm{R}}\right)$ which varies little with time is in the range of $92.2-93.8 \%$ for the whole year, and this value is larger than the coating absorptivity. This is because the cavity effect which can cause an increase of the solar power absorption physically improves the optical efficiency, which is not significantly affected by the time in a year.

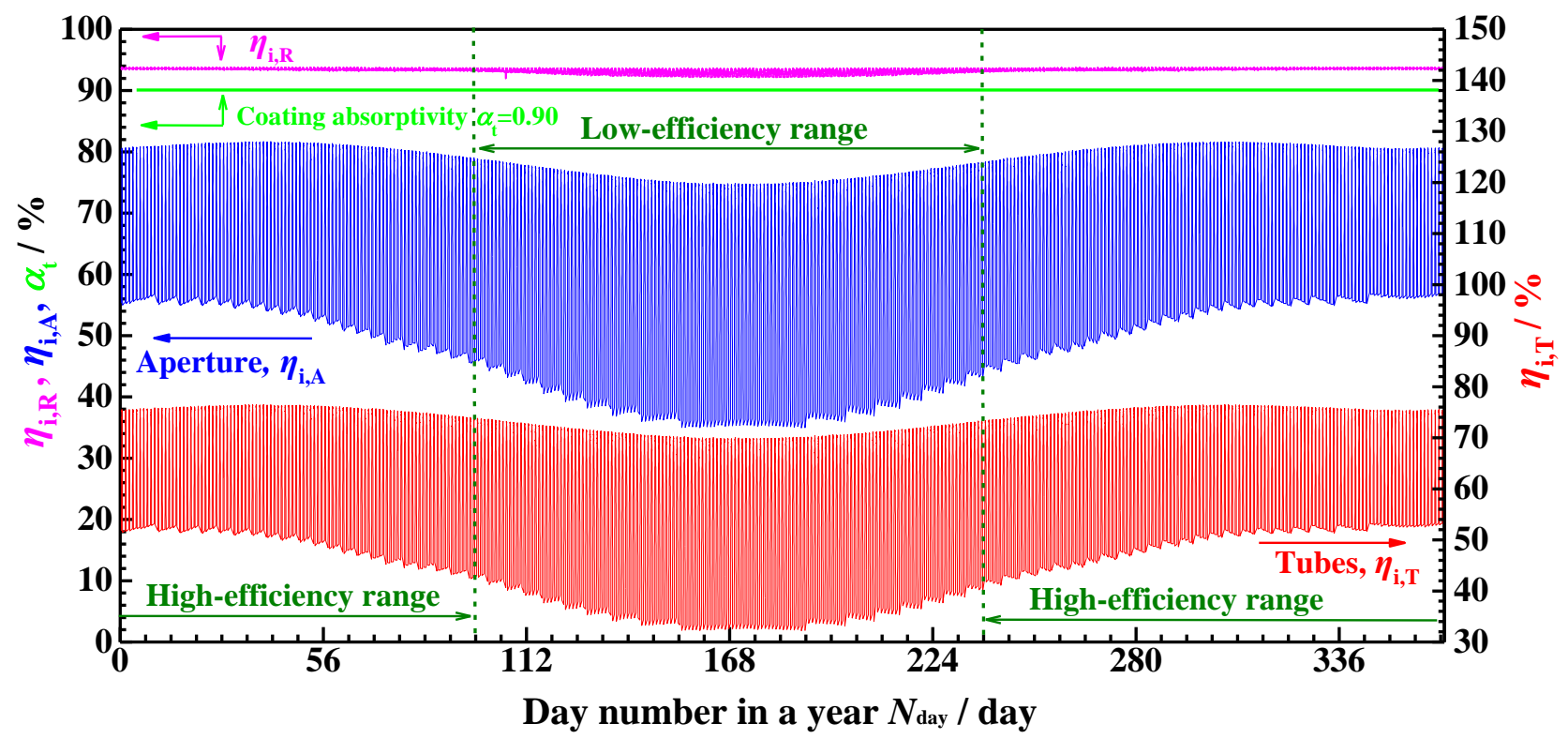

Fig. 20. Variations of instantaneous efficiencies $\left(\eta_{\mathrm{i}, \mathrm{A}}, \eta_{\mathrm{i}, \mathrm{T}}\right.$ and $\left.\eta_{\mathrm{i}, \mathrm{R}}\right)$ in a year.

Figure 21 illustrates the variations of the daily efficiencies $\left(\eta_{\mathrm{d}, \mathrm{A}}, \eta_{\mathrm{d}, \mathrm{T}}\right)$ in a year. There are two peaks and one valley for each efficiency curve, where the valley is at around the summer solstice, and the peaks are in spring and autumn. It can be found that the maximum values of $\eta_{\mathrm{d}, \mathrm{A}}$ and $\eta_{\mathrm{d}, \mathrm{T}}$ are $75.2 \%$ and $70.4 \%$, respectively. And the corresponding minimum values are $64.9 \%$ and $60.6 \%$, respectively. These variations of the curves are specially designed for obtaining a high yearly optical efficiency. From present simulation, it is found that the $\eta_{\mathrm{y}, \mathrm{A}}$ of $70.5 \%$ and $\eta_{\mathrm{y}, \mathrm{T}}$ of $65.9 \%$ can be achieved by DAHAN plant. 


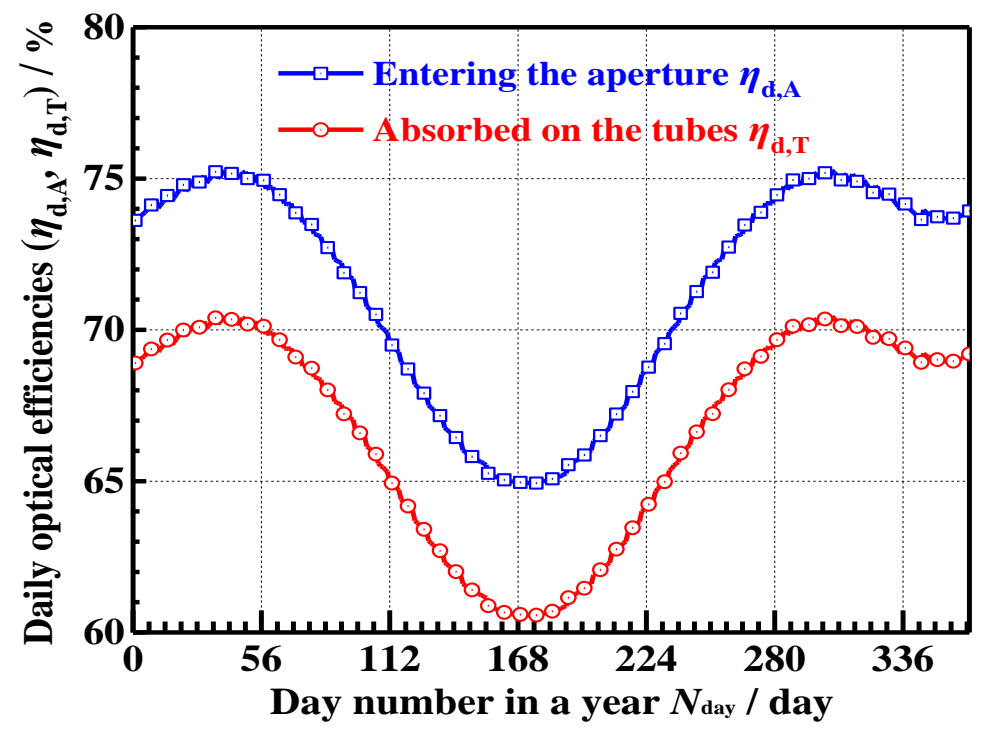

464

Fig. 21. The variations of daily efficiencies $\left(\eta_{\mathrm{d}, \mathrm{A}}, \eta_{\mathrm{d}, \mathrm{T}}\right)$ in a year.

\subsection{Impact of cavity effect on real-time efficiency}

The impact of the cavity effect which refers to the multiple reflections and absorptions among the tubes and walls on the instantaneous efficiency / effective absorptivity of the MTCR ( $\left.\eta_{\mathrm{i}, \mathrm{R}}\right)$, the optical loss $\left(Q_{\mathrm{i}, \text { loss }}\right)$ of the MTCR, and the instantaneous efficiency $\left(\eta_{\mathrm{i}, \mathrm{T}}\right)$ for the power absorbed by the tubes $\left(Q_{i j, T}\right)$ is further discussed in this section.

Figure 22 shows the variations of $\eta_{\mathrm{i}, \mathrm{R}}$ and $Q_{\mathrm{i}, \text { loss }}$ against the coating absorptivity $\left(\alpha_{\mathrm{t}}\right)$ at $t_{\mathrm{s}}=12$, spring equinox. It is seen that the $\eta_{\mathrm{i}, \mathrm{R}}$ considering cavity effect is larger than that which ignores cavity effect at the same $\alpha_{\mathrm{t}}$. This is because the $Q_{\mathrm{i}, \text { loss }}$ is reduced by the cavity effect when the cavity effect is considered. For example, $Q_{\mathrm{i}, \text { loss }}$ decreases from $2748 \mathrm{~kW}$ to $1707 \mathrm{~kW}$ after considering the cavity effect at $\alpha_{\mathrm{t}}=0.65$, and the corresponding increments of the absorbed power $\left(Q_{i j, \mathrm{~T}}\right), \eta_{\mathrm{i}, \mathrm{R}}$ and $\eta_{\mathrm{i}, \mathrm{T}}$ are $1041 \mathrm{~kW}, 13.5$ percent and 10.8 percent, respectively. It is also seen that the decrement of $Q_{\mathrm{i}, \text { loss }}$ due to cavity effect becomes less when $\alpha_{\mathrm{t}}$ is higher. For instance, the cavity effect makes the increments of $Q_{i j, \mathrm{~T}}, \eta_{\mathrm{i}, \mathrm{R}}$ and $\eta_{\mathrm{i}, \mathrm{T}}$ being $340 \mathrm{~kW}, 4.4$ percent and 3.5 percent at $\alpha_{\mathrm{t}}=0.90$, respectively. Therefore, it is clear that the impact of cavity effect is more significant at low $\alpha_{\mathrm{t}}$ than that at high $\alpha_{\mathrm{t}}$. The above results quantitatively reveal the impact of cavity effect on the MTCR's performance, which show that the optical loss can be reduced greatly due to cavity effect, especially when $\alpha_{\mathrm{t}}$ is relatively low. 


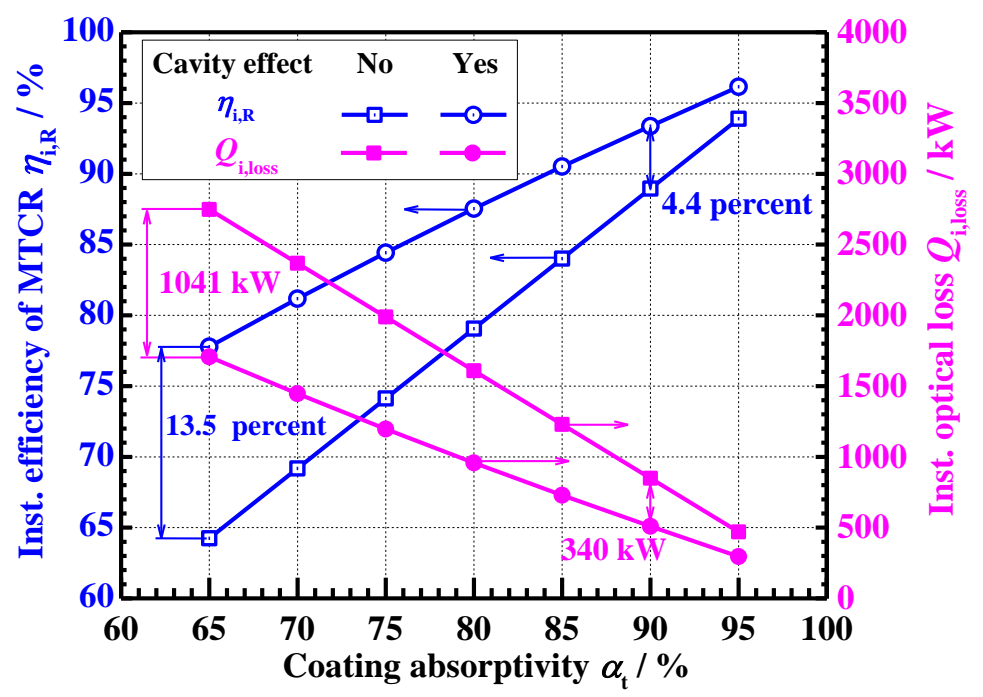

Fig. 22. Variations of $\eta_{\mathrm{i}, \mathrm{T}}$ and $Q_{\mathrm{i}, \text { loss }}$ with $\alpha_{\mathrm{t}}$ at $t_{\mathrm{s}}=12$, spring equinox $\left(D N I=961 \mathrm{~W} \cdot \mathrm{m}^{-2}\right)$.

Figure 23 illustrates the variations of $\eta_{\mathrm{i}, \mathrm{R}}$ and $Q_{\mathrm{i}, \text { loss }}$ on spring equinox with $\alpha_{\mathrm{t}}=0.90$. It is seen that the decrement of $Q_{i, l o s s}$ is in the range of $100-359 \mathrm{~kW}$ after considering the cavity effect, and the corresponding increment of $\eta_{\mathrm{i}, \mathrm{R}}$ is within 4.1-4.7 percent. Moreover, it is seen that $\eta_{\mathrm{i}, \mathrm{R}}$ is smaller than $\alpha_{\mathrm{t}}$ when the cavity effect is ignored. This is because some rays entering the aperture hit the cavity walls rather that the tubes, and these rays will never be absorbed by the tubes when the cavity effect is ignored. The increment of $\eta_{\mathrm{i}, \mathrm{T}}$ can also be obtained by considering the variation of $\eta_{\mathrm{i}, \mathrm{A}}$ in

Fig. 18. It is found that this increment is in the range of 2.0-3.8 percent.

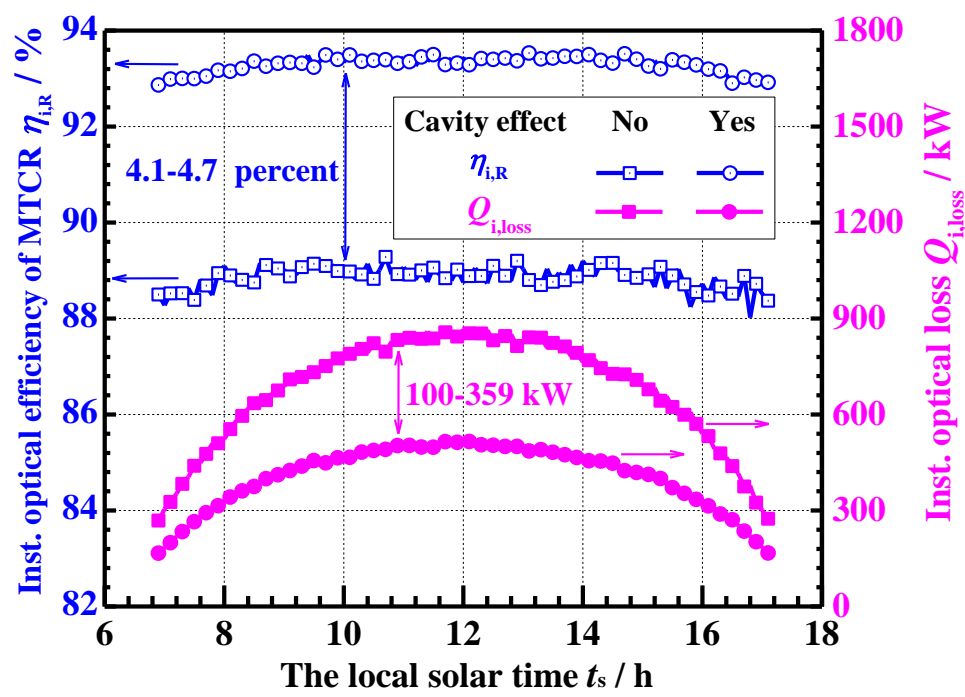

Fig. 23. Variations of $\eta_{\mathrm{i}, \mathrm{R}}$ and $Q_{\mathrm{i}, \text { loss }}$ on spring equinox with $\alpha_{\mathrm{t}}=0.90$.

In summary, the evaluation of the real-time optical performance for an realistic SPT using the present model has been illustrated above, and the results indicate that this model is an exercisable 
and useful tool for predicting both the detailed real-time solar flux which is important for the performance optimization and safe operation, and the real-time efficiency which is important for the system design. Some useful suggestions are also offered from the results. In addition, the model can also be applied in the design process of a SPT in the following way. First, the SPT can be designed in the traditional way. Then, the optical performance can be evaluated by present model. Finally, the original design can be revised based on the evaluation results.

\section{Conclusions}

This work focuses on developing a model to analyze the real-time optical performance of a solar power tower (SPT) with a multi-tube cavity receiver (MTCR). After validation, the real-time optical performance of DAHAN plant was studied to illustrate the application of the model. The following conclusions are derived.

(1) The real-time solar flux distribution in the MTCR exhibits a great non-uniform characteristic, and the maximum flux $\left(q_{1, \max }\right)$ on the tubes is up to $5.141 \times 10^{5} \mathrm{~W} \cdot \mathrm{m}^{-2}$.

(2) A tracking-error model which treats the tracking errors as the errors of the tracking angles is recommended to SPT for considering the random effects of the errors on the flux uniformity and efficiency.

(3) The multi-point aiming strategy which can greatly homogenize the solar flux compared to the traditional one-point strategy is recommended to SPT. The maldistribution index and $q_{1, \max }$ on the tubes can be reduced by $31.6 \%$ and $10.5 \%$, respectively, with only a 1 percent drop in efficiency at typical condition.

(4) The cavity effect can improve the optical efficiency throughout the whole year, and the effective absorptivity is 2.2-3.8 percent higher than coating absorptivity. Study on coating absorptivity indicates that the smaller the absorptivity is, the more distinct the effect is. Further studies on the optical efficiencies indicate that DAHAN can achieve the yearly efficiency of $65.9 \%$.

(5) The validation study and simulation results indicate that the present model is reliable and suitable for dealing with the complex geometry and optical processes in the SPT with a MTCR, and it can predicts both the detailed solar flux and the real-time efficiency appropriately. 


\section{Acknowledgements}

The study is supported by the funding for Key Project of National Natural Science Foundation of China (No.51436007) and the Major Program of the National Natural Science Foundation of China (No. 51590902).

\section{Appendix}

The transformation matrixes among the seven Cartesian right-handed coordinate systems are summarized as follows:

(1) $\boldsymbol{M}_{1}$ and $\boldsymbol{M}_{2}$ are the transformation matrixes from $X_{\mathrm{i}} Y_{\mathrm{i}} Z_{\mathrm{i}}$ to $X_{\mathrm{g}} Y_{\mathrm{g}} Z_{\mathrm{g}}$ :

$$
\begin{aligned}
& \boldsymbol{M}_{1}=\left[\begin{array}{ccc}
1 & 0 & 0 \\
0 & \cos \left(\pi / 2-\alpha_{\mathrm{s}}\right) & -\sin \left(\pi / 2-\alpha_{\mathrm{s}}\right) \\
0 & \sin \left(\pi / 2-\alpha_{\mathrm{s}}\right) & \cos \left(\pi / 2-\alpha_{\mathrm{s}}\right)
\end{array}\right] \\
& \boldsymbol{M}_{2}=\left[\begin{array}{ccc}
\cos \left(A_{\mathrm{s}}+\pi / 2\right) & -\sin \left(A_{\mathrm{s}}+\pi / 2\right) & 0 \\
\sin \left(A_{\mathrm{s}}+\pi / 2\right) & \cos \left(A_{\mathrm{s}}+\pi / 2\right) & 0 \\
0 & 0 & 1
\end{array}\right]
\end{aligned}
$$

where $\alpha_{\mathrm{s}}$ and $A_{\mathrm{s}}$ are the solar altitude and azimuth.

(2) $\boldsymbol{M}_{3}$ and $\boldsymbol{M}_{4}$ are the transformation matrixes from $X_{\mathrm{g}} Y_{\mathrm{g}} Z_{\mathrm{g}}$ to $X_{\mathrm{h}} Y_{\mathrm{h}} Z_{\mathrm{h}}$ :

$$
\boldsymbol{M}_{3}=\left[\begin{array}{ccc}
\cos \left(A_{\mathrm{h}}+\pi / 2\right) & \sin \left(A_{\mathrm{h}}+\pi / 2\right) & 0 \\
-\sin \left(A_{\mathrm{h}}+\pi / 2\right) & \cos \left(A_{\mathrm{h}}+\pi / 2\right) & 0 \\
0 & 0 & 1
\end{array}\right]
$$

$$
\boldsymbol{M}_{4}=\left[\begin{array}{ccc}
1 & 0 & 0 \\
0 & \cos \left(\pi / 2-\alpha_{\mathrm{h}}\right) & \sin \left(\pi / 2-\alpha_{\mathrm{h}}\right) \\
0 & -\sin \left(\pi / 2-\alpha_{\mathrm{h}}\right) & \cos \left(\pi / 2-\alpha_{\mathrm{h}}\right)
\end{array}\right]
$$

where $\alpha_{\mathrm{h}}$ and $A_{\mathrm{h}}$ are the altitude and azimuth of the heliostat's center normal.

(3) $M_{5}$ and $M_{6}$ are the transformation matrixes to introduce slope error:

$$
\begin{aligned}
& \boldsymbol{M}_{5}=\left[\begin{array}{ccc}
1 & 0 & 0 \\
0 & \cos \theta_{2} & -\sin \theta_{2} \\
0 & \sin \theta_{2} & \cos \theta_{2}
\end{array}\right], \boldsymbol{M}_{6}=\left[\begin{array}{ccc}
\cos \left(\theta_{1}+\pi / 2\right) & -\sin \left(\theta_{1}+\pi / 2\right) & 0 \\
\sin \left(\theta_{1}+\pi / 2\right) & \cos \left(\theta_{1}+\pi / 2\right) & 0 \\
0 & 0 & 1
\end{array}\right] \\
& \theta_{1}= \begin{cases}\cos ^{-1}\left(\cos \alpha_{\mathrm{h}, \text { ideal }} / \sqrt{\cos \alpha_{\mathrm{h}, \text { ideal }}^{2}+\cos \beta_{\mathrm{h}, \text { ideal }}^{2}}\right) & , \cos \beta_{\mathrm{h}, \text { ideal }} \geq 0 \\
2 \pi-\cos ^{-1}\left(\cos \alpha_{\mathrm{h}, \text { ideal }} / \sqrt{\cos \alpha_{\mathrm{h}, \text { ideal }}^{2}+\cos \beta_{\mathrm{h}, \text { ideal }}^{2}}\right) & \cos \beta_{\mathrm{h}, \text { ideal }}<0\end{cases} \\
& \theta_{2}=\gamma_{\mathrm{h}, \text { ideal }}
\end{aligned}
$$




$$
\boldsymbol{N}_{\mathrm{h}, \text { ideal }}=\left[\begin{array}{l}
\cos \alpha_{\mathrm{h}, \text { ideal }} \\
\cos \beta_{\mathrm{h}, \text { ideal }} \\
\cos \gamma_{\mathrm{h}, \text { ideal }}
\end{array}\right]=\left[\begin{array}{l}
-x_{\boldsymbol{P}, \mathrm{h}} / \sqrt{x_{P, \mathrm{~h}}^{2}+y_{P, \mathrm{~h}}^{2}+\left(z_{P, \mathrm{~h}}-2 D_{H, \boldsymbol{O}}\right)^{2}} \\
-y_{\boldsymbol{P}, \mathrm{h}} / \sqrt{x_{P, \mathrm{~h}}^{2}+y_{P, \mathrm{~h}}^{2}+\left(z_{P, \mathrm{~h}}-2 D_{H, \boldsymbol{O}}\right)^{2}} \\
-\left(z_{P, \mathrm{~h}}-2 D_{\boldsymbol{H}, \boldsymbol{O}}\right) / \sqrt{x_{P, \mathrm{~h}}^{2}+y_{P, \mathrm{~h}}^{2}+\left(z_{P, \mathrm{~h}}-2 D_{H, \boldsymbol{O}}\right)^{2}}
\end{array}\right]
$$

where $\theta_{1}$ and $\theta_{2}$ are angle variables; $\boldsymbol{N}_{\mathrm{h}, \text { ideal }}$ is the ideal normal vector at $\boldsymbol{P}_{\mathrm{h}}=\left[\begin{array}{lll}x_{\boldsymbol{P}, \mathrm{h}} & y_{\boldsymbol{P}, \mathrm{h}} & z_{\boldsymbol{P}, \mathrm{h}}\end{array}\right]^{\mathrm{T}}$.

(4) $\boldsymbol{M}_{7}$ and $\mathbf{M}_{8}$ are the transformation matrixes from $X_{\mathrm{h}} Y_{\mathrm{h}} Z_{\mathrm{h}}$ to $X_{\mathrm{g}} Y_{\mathrm{g}} Z_{\mathrm{g}}$ :

$$
\begin{aligned}
& \boldsymbol{M}_{7}=\left[\begin{array}{ccc}
1 & 0 & 0 \\
0 & \cos \left(\pi / 2-\alpha_{\mathrm{h}}\right) & -\sin \left(\pi / 2-\alpha_{\mathrm{h}}\right) \\
0 & \sin \left(\pi / 2-\alpha_{\mathrm{h}}\right) & \cos \left(\pi / 2-\alpha_{\mathrm{h}}\right)
\end{array}\right] \\
& \boldsymbol{M}_{8}=\left[\begin{array}{ccc}
\cos \left(A_{\mathrm{h}}+\pi / 2\right) & -\sin \left(A_{\mathrm{h}}+\pi / 2\right) & 0 \\
\sin \left(A_{\mathrm{h}}+\pi / 2\right) & \cos \left(A_{\mathrm{h}}+\pi / 2\right) & 0 \\
0 & 0 & 1
\end{array}\right]
\end{aligned}
$$

(5) $M_{9}$ is the transformation matrix from $X_{\mathrm{g}} Y_{\mathrm{g}} Z_{\mathrm{g}}$ to $X_{\mathrm{r}} Y_{\mathrm{r}} Z_{\mathrm{r}}$ :

$$
\boldsymbol{M}_{9}=\left[\begin{array}{ccc}
1 & 0 & 0 \\
0 & \cos \left(\frac{\pi}{2}-\alpha_{\mathrm{r}}\right) & \sin \left(\frac{\pi}{2}-\alpha_{\mathrm{r}}\right) \\
0 & -\sin \left(\frac{\pi}{2}-\alpha_{\mathrm{r}}\right) & \cos \left(\frac{\pi}{2}-\alpha_{\mathrm{r}}\right)
\end{array}\right]\left[\begin{array}{ccc}
0 & 1 & 0 \\
-1 & 0 & 0 \\
0 & 0 & 1
\end{array}\right]
$$

where $\alpha_{\mathrm{r}}$ is the altitude of the MTCR.

(6) $\boldsymbol{M}_{10}$ and $\boldsymbol{M}_{11}$ are the transformation matrixes from $X_{\mathrm{r}} Y_{\mathrm{r}} Z_{\mathrm{r}}$ to $X_{\mathrm{t}} Y_{\mathrm{t}} Z_{\mathrm{t}}$ :

$$
\begin{aligned}
& \boldsymbol{M}_{10}=\left[\begin{array}{ccc}
\cos \left(A_{\mathrm{t}, \mathrm{r}}+\pi / 2\right) & \sin \left(A_{\mathrm{t}, \mathrm{r}}+\pi / 2\right) & 0 \\
-\sin \left(A_{\mathrm{t}, \mathrm{r}}+\pi / 2\right) & \cos \left(A_{\mathrm{t}, \mathrm{r}}+\pi / 2\right) & 0 \\
0 & 0 & 1
\end{array}\right] \\
& \boldsymbol{M}_{11}=\left[\begin{array}{ccc}
1 & 0 & 0 \\
0 & \cos \left(\pi / 2-\alpha_{\mathrm{t}, \mathrm{r}}\right) & \sin \left(\pi / 2-\alpha_{\mathrm{t}, \mathrm{r}}\right) \\
0 & -\sin \left(\pi / 2-\alpha_{\mathrm{t}, \mathrm{r}}\right) & \cos \left(\pi / 2-\alpha_{\mathrm{t}, \mathrm{r}}\right)
\end{array}\right]
\end{aligned}
$$

where $\alpha_{\mathrm{t}, \mathrm{r}}$ and $A_{\mathrm{t}, \mathrm{r}}$ are the altitude and azimuth of the tube in $X_{\mathrm{r}} Y_{\mathrm{r}} Z_{\mathrm{r}}$, respectively, as shown in Fig. 3.

For present MTCR, $\alpha_{\mathrm{t}, \mathrm{r}}=90^{\circ}$ and $A_{\mathrm{t}, \mathrm{r}}=-90^{\circ}$ for all the tubes.

(7) $\boldsymbol{M}_{12}$ is the transformation matrix from $X_{1} Y_{1} Z_{1}$ to $X_{\mathrm{t}} Y_{\mathrm{t}} Z_{\mathrm{t}}$ : 


$$
\boldsymbol{M}_{12}=\left[\begin{array}{ccc}
\cos \theta_{\mathrm{t}} & 0 & \sin \theta_{\mathrm{t}} \\
0 & 1 & 0 \\
-\sin \theta_{\mathrm{t}} & 0 & \cos \theta_{\mathrm{t}}
\end{array}\right], \theta_{\mathrm{t}}=\left\{\begin{array}{l}
\operatorname{arcos}\left(z_{\boldsymbol{P}, \mathrm{t}} / r_{\mathrm{t}}\right), x_{\boldsymbol{P}, \mathrm{t}} \geq 0 \\
-\operatorname{arcos}\left(z_{P, \mathrm{t}} / r\right), x_{\boldsymbol{P}, \mathrm{t}}<0
\end{array}\right.
$$

553 where $\boldsymbol{P}_{\mathrm{t}, \mathrm{t}}=\left[\begin{array}{lll}x_{P, \mathrm{t}} & y_{P, \mathrm{t}} & z_{P, \mathrm{t}}\end{array}\right]^{\mathrm{T}}$ the intersection a ray and a tube in $X_{\mathrm{t}} Y_{\mathrm{t}} Z_{\mathrm{t}} ; \theta_{\mathrm{t}}$ is the angle shown in Fig.

$5543, r_{\mathrm{t}}$ is the tube radius.

(8) $\boldsymbol{M}_{13}$ and $\mathbf{M}_{14}$ are the transformation matrixes from $X_{\mathrm{t}} Y_{\mathrm{t}} Z_{\mathrm{t}}$ to $X_{\mathrm{r}} Y_{\mathrm{r}} Z_{\mathrm{r}}$ :

556

$$
\boldsymbol{M}_{13}=\left[\begin{array}{ccc}
1 & 0 & 0 \\
0 & \cos \left(\pi / 2-\alpha_{\mathrm{t}, \mathrm{r}}\right) & -\sin \left(\pi / 2-\alpha_{\mathrm{t}, \mathrm{r}}\right) \\
0 & \sin \left(\pi / 2-\alpha_{\mathrm{t}, \mathrm{r}}\right) & \cos \left(\pi / 2-\alpha_{\mathrm{t}, \mathrm{r}}\right)
\end{array}\right]
$$

$$
\boldsymbol{M}_{14}=\left[\begin{array}{ccc}
\cos \left(A_{\mathrm{t}, \mathrm{r}}+\pi / 2\right) & -\sin \left(A_{\mathrm{t}, \mathrm{r}}+\pi / 2\right) & 0 \\
\sin \left(A_{\mathrm{t}, \mathrm{r}}+\pi / 2\right) & \cos \left(A_{\mathrm{t}, \mathrm{r}}+\pi / 2\right) & 0 \\
0 & 0 & 1
\end{array}\right]
$$

$\begin{array}{ll}\boldsymbol{A}, \boldsymbol{B}, \boldsymbol{C}, \boldsymbol{D}, \boldsymbol{E} & \text { aiming points of the heliostats } \\ A_{\mathrm{s}} & \text { solar azimuth }\left(\mathrm{rad},{ }^{\circ}\right) \\ A_{\mathrm{h}} & \text { azimuth of heliostat's center normal }\left(\mathrm{rad},{ }^{\circ}\right) \\ D N I & \text { Direct Normal Irradiance }\left(\mathrm{W} \cdot \mathrm{m}^{-2}\right) \\ d & \text { aiming point coordinate value }(\mathrm{m}) \\ e_{\mathrm{p}} & \text { power carried by each photon }(\mathrm{W}) \\ E_{\mathrm{t}}(i) & \text { power absorbed by } i \text { th tube } \\ \boldsymbol{G} & \text { tower base } \\ \boldsymbol{H} & \text { center of each heliostat } \\ H_{o} & \text { height of aperture center (m) } \\ \boldsymbol{I}, \boldsymbol{N}, \boldsymbol{R} & \text { incident / normal / reflection vector } \\ \boldsymbol{M}_{1} \sim \mathbf{M}_{14} & \text { matrix } \\ L_{\mathrm{h}} & \text { height of the heliostat (m) } \\ n_{\mathrm{t},} n_{\mathrm{h}} & \text { number of absorber tube / heliostat } \\ N_{\mathrm{p}} & \text { total number of the photon traced in the field } \\ N_{\text {day }} & \text { the number of the day in a year } \\ \boldsymbol{O} & \text { aperture center } \\ \boldsymbol{P} & \text { point }\end{array}$




$\begin{array}{ll}Q & \text { solar power }(\mathrm{W}) \\ q_{1} & \text { local solar flux }\left(\mathrm{W} \cdot \mathrm{m}^{-2}\right) \\ \boldsymbol{R}_{\mathrm{te}} & \text { tracking error }(\mathrm{rad}) \\ S_{\mathrm{e}} & \text { area of each element }\left(\mathrm{m}^{2}\right) \\ t_{\mathrm{S}} & \text { solar time }(\mathrm{h}) \\ W_{\mathrm{h}} & \text { width of the heliostat }(\mathrm{m}) \\ X, Y, Z & \text { Cartesian coordinates }(\mathrm{m})\end{array}$

\section{Greek symbols}

\begin{tabular}{|c|c|}
\hline$\alpha_{\mathrm{s}}$ & solar altitude $\left(\mathrm{rad},{ }^{\circ}\right)$ \\
\hline$\alpha_{\mathrm{h}}$ & altitude of heliostat's center normal $\left(\mathrm{rad},{ }^{\circ}\right)$ \\
\hline$\alpha_{\mathrm{r}}$ & altitude of the MTCR $\left(\mathrm{rad},{ }^{\circ}\right)$ \\
\hline$\alpha_{\mathrm{t}}, \alpha_{\mathrm{w}}$ & absorptivity of coating / cavity wall \\
\hline$\delta$ & declination $\left(\mathrm{rad},{ }^{\circ}\right)$ \\
\hline$\eta$ & efficiency $(\%)$ \\
\hline$\eta_{\text {att }}$ & atmospheric attenuation $(\%)$ \\
\hline$\theta, \theta_{\mathrm{t}}$ & angle variables on the tubes $\left({ }^{\circ}\right)$ \\
\hline$\theta_{\mathrm{i}}$ & incident angle on surface $\left(\mathrm{rad},{ }^{\circ}\right)$ \\
\hline$\theta_{\mathrm{h}}$ & heliostat azimuth in the field $\left(\mathrm{rad},{ }^{\circ}\right)$ \\
\hline$\xi$ & uniform random number between 0 and 1 \\
\hline$\rho_{\mathrm{t}, \mathrm{s},} \rho_{\mathrm{t}, \mathrm{d}}$ & specular / diffuse reflectance of coating \\
\hline$\rho \mathrm{h} 1, \rho \mathrm{h} 2$ & reflectance / cleanliness of heliostat \\
\hline$\rho_{\mathrm{w}, \mathrm{s},}, \rho_{\mathrm{w}, \mathrm{d}}$ & specular / diffuse reflectance of the wall \\
\hline$\sigma_{\mathrm{E}}$ & energy maldistribution index among the tubes $(\%)$ \\
\hline$\sigma_{\text {te }}, \sigma_{\text {se }}$ & standard deviation of tracking / slope error (mrad) \\
\hline$\varphi$ & local latitude $\left(\mathrm{rad},{ }^{\circ}\right)$ \\
\hline$\omega$ & hour angle $\left({ }^{\circ}\right)$ \\
\hline
\end{tabular}

\section{Subscripts}

g, h, r, t, w, $1 \quad$ ground / heliostat / receiver / tube / wall / local parameter

i instantaneous or incident parameter

d,y daily/yearly parameter

$\mathrm{T}, \mathrm{H}, \mathrm{R} \quad$ tube / heliostat field/ receiver symbol for efficiency

560 [1] McGlade C, Ekins P. The geographical distribution of fossil fuels unused when limiting global warming to 2 degrees 561 C. Nature. 2015;517:187-90. 
[2] Li YS. A liquid-electrolyte-free anion-exchange membrane direct formate-peroxide fuel cell. Int J Hydrogen Energ. 563 2016;41:3600-4.

564 [3] Li MJ, Song CX, Tao WQ. A hybrid model for explaining the short-term dynamics of energy efficiency of China's 565 thermal power plants. Appl Energ. 2016;169:738-47.

566 [4] Zheng ZJ, He Y, He YL, Wang K. Numerical optimization of catalyst configurations in a solar parabolic trough 567 receiver-reactor with non-uniform heat flux. Sol Energ. 2015;122:113-25.

568 [5] Li MJ, He YL, Tao WQ. Modeling a hybrid methodology for evaluating and forecasting regional energy efficiency in 569 China. Appl Energ. 2015:DOI:10.1016/j.apenergy.2015.11.082.

[6] Daabo AM, Al Jubori A, Mahmoud S, Al-Dadah RK. Development of three-dimensional optimization of a small-scale radial turbine for solar powered Brayton cycle application. Appl Therm Eng. 2017;111:718-33.

[7] Cheng ZD, He YL, Du BC, Wang K, Liang Q. Geometric optimization on optical performance of parabolic trough solar collector systems using particle swarm optimization algorithm. Appl Energ. 2015;148:282-93.

[8] Yan J. Handbook of clean energy systems Volume 1: Renewable Energy. 1st ed. New York: Wiley; 2015.

[9] Salomé A, Chhel F, Flamant G, Ferrière A, Thiery F. Control of the flux distribution on a solar tower receiver using an optimized aiming point strategy: Application to THEMIS solar tower. Sol Energ. 2013;94:352-66.

[10] Yu Q, Wang Z, Xu E, Li X, Guo M. Modeling and dynamic simulation of the collector and receiver system of 1MWe DAHAN solar thermal power tower plant. Renew Energ. 2012;43:18-29.

579 [11] Zheng ZJ, He YL, Li YS. An entransy dissipation-based optimization principle for solar power tower plants. SCI CHINA SER E. 2014;57:773-83.

[12] Cui FQ, He YL, Cheng ZD, Li YS. Study on combined heat loss of a dish receiver with quartz glass cover. Appl Energ. 2013;112:690-6. porous-medium receiver heated by multi-dish concentrator. Int Commun Heat Mass. 2016;75:36-41.

[14] Daabo AM, Mahmoud S, Al-Dadah RK. The optical efficiency of three different geometries of a small scale cavity receiver for concentrated solar applications. Appl Energ. 2016;179:1081-96.

[15] Daabo AM, Mahmoud S, Al-Dadah RK. The effect of receiver geometry on the optical performance of a small-scale solar cavity receiver for parabolic dish applications. Energy. 2016;114:513-25.

[16] Cheng ZD, He YL, Qiu Y. A detailed nonuniform thermal model of a parabolic trough solar receiver with two halves and two inactive ends. Renew Energ. 2015;74:139-47. restrain of tube receiver for parabolic trough solar collector by using asymmetric outward convex corrugated tube.

[18] Wang FQ, Lai QZ, Han HZ, Tan JY. Parabolic trough receiver with corrugated tube for improving heat transfer and thermal deformation characteristics. Appl Energ. 2016;164:411-24.

[19] Bellos E, Tzivanidis C, Antonopoulos KA, Gkinis G. Thermal enhancement of solar parabolic trough collectors by using nanofluids and converging-diverging absorber tube. Renew Energ. 2016;94:213-22. [20] Qiu Y, He YL, Wu M, Zheng ZJ. A comprehensive model for optical and thermal characterization of a linear Fresnel solar reflector with a trapezoidal cavity receiver. Renew Energ. 2016;97:129-44.

600 [21] Abbas R, Montes MJ, Rovira A, Martínez-Val J. Parabolic trough collector or linear Fresnel collector? A 601 comparison of optical features including thermal quality based on commercial solutions. Sol Energ. 2016;124:198-215.

602 [22] Bellos E, Mathioulakis E, Tzivanidis C, Belessiotis V, Antonopoulos KA. Experimental and numerical investigation 603 of a linear Fresnel solar collector with flat plate receiver. Energ Convers Manag. 2016;130:44-59. 
[23] Vignarooban K, Xu X, Wang K, Molina EE, Li P, Gervasio D, et al. Vapor pressure and corrosivity of ternary metal-chloride molten-salt based heat transfer fluids for use in concentrating solar power systems. Appl Energ. 2015;159:206-13.

[24] Li P, Van Lew J, Karaki W, Chan C, Stephens J, Wang Q. Generalized charts of energy storage effectiveness for thermocline heat storage tank design and calibration. Sol Energ. 2011;85:2130-43.

[25] Behar O, Khellaf A, Mohammedi K. A review of studies on central receiver solar thermal power plants. Renew Sust Energ Rev. 2013;23:12-39.

[26] Cheng ZD, He YL, Cui FQ. Numerical investigations on coupled heat transfer and synthetical performance of a pressurized volumetric receiver with MCRT-FVM method. Appl Therm Eng. 2013;50:1044-54.

[27] Zheng ZJ, Li MJ, He YL. Thermal analysis of solar central receiver tube with porous inserts and non-uniform heat flux. Appl Energ. 2015:DOI:10.1016/j.apenergy.2015.11.039.

[28] Lim JH, Hu E, Nathan GJ. Impact of start-up and shut-down losses on the economic benefit of an integrated hybrid solar cavity receiver and combustor. Appl Energ. 2016;164:10-20.

[29] Xu C, Wang ZF, Li X, Sun FH. Energy and exergy analysis of solar power tower plants. Appl Therm Eng. 2011;31:3904-13.

[30] Rodríguez-Sánchez MR, Soria-Verdugo A, Almendros-Ibáñez JA, Acosta-Iborra A, Santana D. Thermal design guidelines of solar power towers. Appl Therm Eng. 2014;63:428-38.

[31] Du BC, He YL, Zheng ZJ, Cheng ZD. Analysis of thermal stress and fatigue fracture for the solar tower molten salt receiver. Appl Therm Eng. 2016;99:741-50.

[32] He YL, Wang K, Du BC, Qiu Y, Liang Q. Non-uniform characteristics of solar flux distribution in the concentrating solar power systems and its corresponding solutions: A review (in Chinese). Chin Sci Bull. 2016;61:3208-37.

[33] Yellowhair J, Ortega JD, Christian JM, Ho CK. Solar optical codes evaluation for modeling and analyzing complex solar receiver geometries. In SPIE Opt Eng Appl: International Society for Optics and Photonics; 2014. 91910M-M-9.

[34] Vant-Hull LL, Izygon ME, Pitman CL. Real-time computation and control of solar flux density on a central receiver (Solar Two)(protection against excess flux density). American Solar Energy Society. Boulder, CO. 1996.

[35] Garcia P, Ferriere A, Bezian JJ. Codes for solar flux calculation dedicated to central receiver system applications: A comparative review. Sol Energ. 2008;82:189-97.

[36] He YL, Xiao J, Cheng ZD, Tao YB. A MCRT and FVM coupled simulation method for energy conversion process in parabolic trough solar collector. Renew Energ. 2011;36:976-85.

[37] Rinaldi F, Binotti M, Giostri A, Manzolini G. Comparison of linear and point focus collectors in solar power plants. Enrgy Proced. 2014;49:1491-500.

[38] Mecit AM, Miller FJ, Whitmore A. Optical analysis and thermal modeling of a window for a small particle solar receiver. Enrgy Proced. 2014;49:457-67.

[39] Yao Z, Wang Z, Lu Z, Wei X. Modeling and simulation of the pioneer 1MW solar thermal central receiver system in China. Renew Energ. 2009;34:2437-46.

[40] Yu Q, Wang Z, Xu E, Zhang H, Lu Z, Wei X. Modeling and simulation of 1MWe solar tower plant's solar flux distribution on the central cavity receiver. Simul Model Pract Th. 2012;29:123-36.

[41] Sanchez-Gonzalez A, Santana D. Solar flux distribution on central receivers: A projection method from analytic function. Renew Energ. 2015;74:576-87.

[42] Cheng ZD, He YL, Cui FQ. A new modelling method and unified code with MCRT for concentrating solar collectors and its applications. Appl Energ. 2013;101:686-98.

[43] Xu E, Yu Q, Wang Z, Yang C. Modeling and simulation of 1 MW DAHAN solar thermal power tower plant. Renew 
Energ. 2011;36:848-57.

[44] Osuna R. Solar thermal industry, success stories and perspectives. Renewable energy for Europe, research in action. European Commission, Brussels 2005.

[45] Zang C, Gong B, Wang Z. Experimental and theoretical study of wind loads and mechanical performance analysis of heliostats. Sol Energ. 2014;105:48-57.

[46] Yu Q, Wang Z, Xu E. Simulation and analysis of the central cavity receiver's performance of solar thermal power tower plant. Sol Energ. 2012;86:164-74.

[47] Badescu V. Theoretical derivation of heliostat tracking errors distribution. Sol Energ. 2008;82:1192-7.

[48] Collado FJ. One-point fitting of the flux density produced by a heliostat. Sol Energ. 2010;84:673-84.

[49] Qiu Y, Li MJ, He YL, Tao WQ. Thermal performance analysis of a parabolic trough solar collector using supercritical $\mathrm{CO} 2$ as heat transfer fluid under non-uniform solar flux. Appl Therm Eng. 2016:DOI:10.1016/j.applthermaleng.2016.09.044.

[50] Stine W, Geyer M. Power From The Sun. http://www.powerfromthesun.net/. 2001.

[51] Qiu Y, He YL, Cheng ZD, Wang K. Study on optical and thermal performance of a linear Fresnel solar reflector using molten salt as HTF with MCRT and FVM methods. Appl Energ. 2015;146:162-73.

[52] He YL, Cui FQ, Cheng ZD, Li ZY, Tao WQ. Numerical simulation of solar radiation transmission process for the solar tower power plant: From the heliostat field to the pressurized volumetric receiver. Appl Therm Eng. 2013;61:583-95.

[53] Xu Y, Cui K, Liu D. The development of a software for solar radiation and its verification by the measurement results on the spot. Energ Tech. 2002;26:237-9.

[54] Belhomme B, Pitz-Paal R, Schwarzbözl P, Ulmer S. A new fast ray tracing tool for high-precision simulation of heliostat fields. J Sol Energ. 2009;131:031002.

[55] Schmitz M, Schwarzbözl P, Buck R, Pitz-Paal R. Assessment of the potential improvement due to multiple apertures in central receiver systems with secondary concentrators. Sol Energ. 2006;80:111-20.

[56] Wang K, He YL, Qiu Y, Zhang YW. A novel integrated simulation approach couples MCRT and Gebhart methods to simulate solar radiation transfer in a solar power tower system with a cavity receiver. Renew Energ. 2016;89:93-107.

[57] Cui FQ, He YL, Cheng ZD, Li YS. Modeling of the dish receiver with the effect of inhomogeneous radiation flux distribution. Heat Transfer Eng. 2014;35:780-90.

[58] Wang F, Shuai Y, Tan H, Yu C. Thermal performance analysis of porous media receiver with concentrated solar irradiation. Int J Heat Mass Tran. 2013;62:247-54.

[59] Binotti M, De Giorgi P, Sanchez D, Manzolini G. Comparison of different strategies for heliostats aiming point in cavity and external tower receivers. J Sol Energ. 2016;138:021008. 